Article

\title{
Free-Radical Photopolymerization of Acrylonitrile Grafted onto Epoxidized Natural Rubber
}

\author{
Rawdah Whba ${ }^{1,2}$, Mohd Sukor Su' ait ${ }^{3}$, Lee Tian Khoon ${ }^{1, * \mathbb{D}}$, Salmiah Ibrahim ${ }^{4}$, Nor Sabirin Mohamed ${ }^{4}$ \\ and Azizan Ahmad 1,5,*
}

check for

updates

Citation: Whba, R.; Su'ait, M.S.; Tian Khoon, L.; Ibrahim, S.; Mohamed,

N.S.; Ahmad, A. Free-Radical Photopolymerization of Acrylonitrile Grafted onto Epoxidized Natural Rubber. Polymers 2021, 13, 660. https://doi.org/10.3390/ polym 13040660

Academic Editor: Vicente Compañ Moreno

Received: 15 January 2021

Accepted: 16 February 2021

Published: 23 February 2021

Publisher's Note: MDPI stays neutral with regard to jurisdictional claims in published maps and institutional affiliations.

Copyright: (c) 2021 by the authors. Licensee MDPI, Basel, Switzerland. This article is an open access article distributed under the terms and conditions of the Creative Commons Attribution (CC BY) license (https:// creativecommons.org/licenses/by/ $4.0 /)$
1 Department of Chemical Sciences, Faculty of Sciences and Technology, Universiti Kebangsaan Malaysia, Bangi 43600, Malaysia; rawdahukm31@gmail.com

2 Department of Chemistry, Faculty of Applied Sciences, Taiz University, Taiz 6803, Yemen

3 Solar Energy Research Institute (SERI), Universiti Kebangsaan Malaysia, Bangi 43600, Malaysia; mohdsukor@ukm.edu.my

4 Centre for Foundation Studies in Science, University of Malaya, Kuala Lumpur 50603, Malaysia; salmiah01@um.edu.my (S.I.); nsabirin@um.edu.my (N.S.M.)

5 Research Center for Quantum Engineering Design, Faculty of Science and Technology, Universitas Airlangga, Surabaya 60286, Indonesia

* Correspondence: tiankhoon@ukm.edu.my (L.T.K.); azizan@ukm.edu.my (A.A.); Tel.: +60-12-7279286 (L.T.K.); $+60-19-3666576$ (A.A.)

Abstract: The exploitation of epoxidized natural rubber (ENR) in electrochemical applications is approaching its limits because of its poor thermo-mechanical properties. These properties could be improved by chemical and/or physical modification, including grafting and/or crosslinking techniques. In this work, acrylonitrile (ACN) has been successfully grafted onto ENR- 25 by a radical photopolymerization technique. The effect of (ACN to ENR) mole ratios on chemical structure and interaction, thermo-mechanical behaviour and that related to the viscoelastic properties of the polymer was investigated. The existence of the $-\mathrm{C} \equiv \mathrm{N}$ functional group at the end-product of $\mathrm{ACN}-\mathrm{g}-$ ENR is confirmed by infrared (FT-IR) and nuclear magnetic resonance (NMR) analyses. An enhanced grafting efficiency $(\sim 57 \%)$ was obtained after ACN was grafted onto the isoprene unit of ENR- 25 and showing a significant improvement in thermal stability and dielectric properties. The viscoelastic behaviour of the sample analysis showed an increase of storage modulus up to $150 \times 10^{3} \mathrm{MPa}$ and the temperature of glass transition $\left(T_{\mathrm{g}}\right)$ was between -40 and $10{ }^{\circ} \mathrm{C}$. The loss modulus, relaxation process, and tan delta were also described. Overall, the ACN-g-ENR shows a distinctive improvement in characteristics compared to ENR and can be widely used in many applications where natural rubber is used but improved thermal and mechanical properties are required. Likewise, it may also be used in electronic applications, for example, as a polymer electrolyte in batteries or supercapacitor.

Keywords: epoxidized natural rubber; radical polymerization; grafting; modified rubber

\section{Introduction}

Natural rubber (NR) is an essential raw material and accounts for over 50,000 various rubber and latex-related products. Under Statistics Malaysia (2020), NR crop production in January 2020 has increased by $13.3 \%$ to 66,232 tonnes compared with previous months [1]. This value is expected to extend beyond the 2nd quarter of 2020 because of the high demand for medical gloves to fight the global pandemic, COVID-19. Amidst the pandemic situation, Malaysia's export of NR in February (2020) surged by 13.1\%, reaching 45,827 tonnes in January [2]. However, the increasing demands cannot be met and maintained in the future by relying solely on natural rubber. Therefore, it is necessary to search for more viable alternatives and innovative solutions that can be established, with superior properties, by chemical modification and cost-effectiveness procedures. Modified rubber, especially more thermally stable derivatives such as epoxide rubber, is highly desirable and may complement the sections of the market share which are currently occupied by synthetic 
rubbers [3]. Currently, there are two commercially available ENRs, i.e., ENR-25 and ENR50 , where 25 and 50 represent mole epoxy content in the ENR structure. ENR is a pivotal polymer owing to its unique mechanical properties and low cost [4]. The existence of epoxide groups in the ENR structure has enhanced the originality of NR properties. This is clear through its improved polarity, good strength, excellent adhesion, high hardness, compatibility blend with other polymers, and good oil and temperature resistance, as well as its low air permeability [5]. Furthermore, ENR offers a variety of potential, particularly in electrochemical applications. This is attributed to the oxygen atom, which promotes the dissociation of salt, and hence provides conductivity while maintaining the adhesion property that can promote good contact between the electrolyte layer and electrode for electronic devices $[6,7]$.

Generally, ENR can be synthesized and obtained by a simple chemical modification. This happens through the interaction of an oxygen atom with the double bonds of the NR chains via in situ epoxidation using an acid and hydrogen peroxide [8]. However, its low $T_{\mathrm{g}}\left(\sim-22^{\circ} \mathrm{C}\right)$ and high molecular weight are considered drawbacks to its solubility and processability [4]. Moreover, all rubbers are sticky and easily deform in warmer conditions but become brittle when cold; this has greatly and adversely affected their degree of elasticity. To overcome these major drawbacks, physical or chemical modifications must be made. For example, modifications include free-radical grafting on ENR to modify it or chemically bonding the rubber chains with another functional polymer via crosslinking and vulcanization processes [9].

To improve the processability and solubility, ENR is further degraded by decreasing its molecular weight, resulting in liquid epoxidized natural rubber (LENR) [4]. Besides this, Lee et al. [10] and Rahman et al. [11,12] have reported that the molecular weight of ENR was successfully decreased via an irradiation process with a UV lamp by breaking the long chains into small chains.

Concurrent with the above objective of improving and developing new, enhanced ENRs, this work focused on grafting radical polymerization via the photopolymerization technique. Photopolymerization is a technique that initiates and propagates a polymerization reaction using light (visible or ultraviolet (UV)) to form a linear or cross-linked polymer structure. The formation of a polymer through a chain reaction caused by light is concerned with direct photoinduced polymerization reactions. As the direct formation of reactive species by light absorption on the monomer is not an efficient path, the initiation stage of the polymerization reaction requires the presence of a photoinitiator capable of producing these reactive species under light excitation. Spectral sensitivity extension (which corresponds to the best match between the light source emission spectrum and the formulation absorption spectrum) can be accomplished by using actives species: their function is to absorb the energy of the light at a wavelength where the photoinitiator is unable to work and pass the excitation. In that case, the reaction is known as a sensitized photoinduced polymerization [13]. It is a method that is widely used to convert the multifunction monomers into insoluble networks that are efficient in many industrial fields, such as films, inks, coatings, and photoresistors [14,15]. Furthermore, it is an inexpensive method, easy to handle, and applies to low-temperature and -pressure requirements [4]. This technique only includes a monomer-soluble initiator and a molecular-weight chain-transfer agent. 2,2-dimethoxy-2-phenyl-acetophenone (DMPA) was used as a photoinitiator in this work because it showed an excellent photopolymerization performance, as stated by Mishra and Yagci [16]. Several studies related to NR grafting also have been reported. Kookarinrat and Paoprasert [17] introduced the grafting of methyl methacrylate (MMA) onto NR latex to ameliorate the stability of NR by saturating the double bonds through grafting and hydrogenation reactions as a one-pot method. Several studies have also been done on MMA-g-ENR $[4,18,19]$. They found that MMA- $g$-ENR has a higher $T_{g}$ (mechanically more stable), better compatibility with curing agents and phase separation and better weathering resistance. 
Additionally, because of the active epoxide on ENR, many crosslinking agents have been used with ENR. At a high-energy electron, irradiation produces a free radical that reacts with the structure of the irradiated rubber and can take place either at epoxide or the $-\mathrm{C}=\mathrm{C}$ - bond [20]. Yin et al. [21] has reported the introduction of the temperature responsiveness to NR with poly(N-isopropyl acrylamide) (PNIPAM) and benzoyl peroxide as a free radical cross-linker. The results displayed a straightforward strategy for crosslinking PNIPAM with NR, and the temperature responsiveness led to the creation of new, responsive, rubber-based materials and extend the range of potential applications.

In the present work, the grafting of acrylonitrile (ACN) onto ENR- 25 as a new grafting polymerization will be synthesized via free-radical photopolymerization and investigated in terms of the chemical and physical characterization. ENR- 25 was chosen because it contains fewer epoxide groups compared to ENR- 50. Eventually, this will provide more alkene double bonds in the polymeric chain for radical polymerization active sites. Previous studies have reported on "physically" crosslinking ENR, but little work has been done on "chemically" grafting ENR- 25. Nonetheless, the presence of an epoxide functional group on the polymeric chain provides more opportunities to utilize natural rubber in various fields, especially in the conductive or permeable membrane. This is because of the existence of an epoxy ring that considers a coordination position for the $\mathrm{Li}^{+}$connection [22]. The ACN monomer has been selected as a grafting agent for this study. This is due to ACN's unique properties, including its high film-ability, transparency, optical clarity, adhesive properties [23], and the highest grafting efficiency compared to vinyl monomers [24]. This research will give a new, broad view of grafting ACN onto ENR-25 via UV photopolymerization, which is anticipated to improve and enhance the thermo-mechanical behaviour, along with its dielectric properties, to prepare a desired membrane with high permittivity and flexibility.

\section{Materials and Methods}

\subsection{Materials}

Figure 1 presents the chemical structure of the epoxidized natural rubber (ENR) used in this work, with about $25 \%$ mole epoxy content (trade as ENR- 25), which was purchased from Malaysia Rubber Board (MRB) (Sungai Buloh, Selangor, Malaysia). Acrylonitrile (ACN) $\left(\mathrm{C}_{3} \mathrm{H}_{3} \mathrm{~N}, \geq 99 \%\right.$, Sigma-Aldrich, Zwijndrecht, Netherlands), toluene $\left(\mathrm{C}_{7} \mathrm{H}_{8}\right.$, $99.5 \%$, Systerm ${ }^{\circledR} \mathrm{Chemar}^{\circledR}$, Shah Alam, Selangor, Malaysia), 2,2-dimethoxy-2-phenylacetophenone (DMPA) $\left(\mathrm{C}_{16} \mathrm{H}_{16} \mathrm{O}_{3}, 99 \%\right.$, Sigma-Aldrich, China China-Mainland), methanol $\left(\mathrm{CH}_{3} \mathrm{OH}, 99.8 \%\right.$, Systerm ${ }^{\circledR} \mathrm{Chemar}^{\circledR}$, Shah Alam, Selangor, Malaysia), basic aluminum oxide $\left(\mathrm{Al}_{2} \mathrm{O}_{3}, 99.9 \%\right.$, Sigma-Aldrich, St. Louis, $\mathrm{MO}$, USA), potassium carbonate $\left(\mathrm{K}_{2} \mathrm{CO}_{3}, 98 \%\right.$, Sigma-Aldrich, St. Louis, Germany), and xylene $\left(\mathrm{C}_{8} \mathrm{H}_{10}, 98.5 \%\right.$, $\mathrm{R} \& \mathrm{M}$ chemicals, Semenyih, Selangor, Malaysia). Both ENR- 25 and ACN were used with further purification.

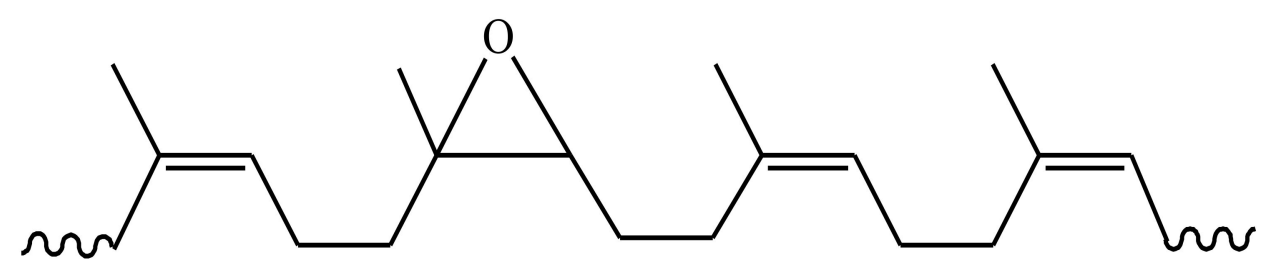

Figure 1. Chemical structure of epoxidized natural rubber (ENR)-25. 


\subsection{Samples Preparation and Characterizations}

The preparation of ACN-g-ENR was carried out in different stages: (1) purification of reagents, (2) synthesis of ACN-g-ENR via radical photopolymerization, and (3) purification of ACN-g-ENR products.

\subsubsection{Purification of Reagents}

About $\sim 20 \mathrm{~g}$ of ENR- 25 was cut into small portions and swelled in SCHOTT DURAN ${ }^{\circledR}$ containing $400 \mathrm{~mL}$ toluene for $24 \mathrm{~h}$. For the next $48 \mathrm{~h}$, the swollen ENR- 25 was continuously stirred at $70{ }^{\circ} \mathrm{C}$, followed by filtration through a cotton gauze pack to separate the gel from the extract. The latter was poured slowly into a beaker containing $800 \mathrm{~mL}$ methanol, while the solution was hand-stirred using a glass rod. The purified ENR- 25 was precipitated and stuck on the glass rod surface. The purified amount was transferred to a petri dish and dried in the fume hood before transfer to the oven, where it was dried for $24 \mathrm{~h}$ at $100{ }^{\circ} \mathrm{C}$. Thereafter, the sample was further dried in a vacuum oven at $50{ }^{\circ} \mathrm{C}$ for two days until the sample achieved a constant weight. The purification of $\mathrm{ACN}$ was conducted using a simple column with cotton fibre, quartz sand and basic aluminium oxide to remove the inhibitor and potassium carbonate, respectively.

\subsubsection{UV Photopolymerization of ACN onto ENR- 25}

The UV photopolymerization of ACN onto ENR- 25 was carried out at different mole ratios of (10:1), (15:1), and (20:1). For $\mathrm{ACN}_{10}$-g-ENR 1 preparation, $1 \mathrm{~g}$ (equivalent to 0.0035 moles) of ENR- 25 was swelled in toluene $(10 \mathrm{~mL})$ overnight. Then, the mixture was stirred for one day, followed by adding $1.86 \mathrm{~g}$ (equivalent to 0.035 moles) of the ACN monomer and DMPA as a photoinitiator. The amount of DMPA ranged from 0.046 to $0.076 \mathrm{~g}$ based on the amount of $\mathrm{ACN}$ used. After that, the mixture was stirred for another $48 \mathrm{~h}$ before exposed to UV irradiation in a UV light box (model RS component $(196-5251))$ with radiation at $383 \mathrm{~nm}(\lambda)$, an intensity of $236 \mathrm{~mW} / \mathrm{cm}^{2}$, and $\mathrm{E}=3.237 \mathrm{eV}$, containing four 60 watt-lamps under a continuous flow of $\mathrm{N}_{2}$ gas for $3 \mathrm{~h}$. The grafted product was then washed with methanol to remove excess unreacted monomer. Finally, the grafted sample was put in a vacuum oven to dry at $55^{\circ} \mathrm{C}$ for $24 \mathrm{~h}$. $\mathrm{ACN}_{15}-\mathrm{g}-\mathrm{ENR}_{1}, \mathrm{ACN}_{20^{-}}$ g-ENR 1 , and polyacrylonitrile (PAN, control sample) were prepared by the procedures described above.

\subsubsection{Purification of ACN-g-ENR Products}

Purification of ACN-g-ENR products was performed by cutting the grafted samples into small pieces and dissolving each ratio in $50 \mathrm{~mL}$ of xylene for $24 \mathrm{~h}$. The mixtures were then heated at $100{ }^{\circ} \mathrm{C}$ with continuous stirring until the samples were completely dissolved. Thereafter, the sample was purified using the same method as ENR- 25 purification. Figure 2 shows synthesis of ACN-g-ENR-grafted samples before and after purification via photopolymerization technique at different mole ratios. A schematic representation of the proposed mechanism of grafting ACN onto ENR- 25 under UV photopolymerization is shown in Scheme 1.

\subsubsection{Mechanism of Reaction}

The mechanism of this work was established by free-radical grafting onto ENR-25. The model of heterogeneous graft polymerization of acrylonitrile onto ENR-25 was initiated by DMPA. It should be noted that Casinos [25] and Bhattacharya et al. [26] have reported that grafting can be accomplished by "grafting from" or "grafting to" or "grafting from-to" approaches.

The "grafting from" approach is achieved by treating a substrate to generate immobilized initiators followed by polymerization (the addition of monomer to polymeric radicals followed by propagation of the grafted radical chains). However, in the "grafting to" approach, the radical homopolymer chains are combined with the polymeric radicals, while the "grafting from-to" approach is achieved by a combination reaction of radical homopolymer chains with grafted radical chains. The proposed mechanism was carried 
out in three main steps: (i) chain initiation; (ii) chain propagation; (iii) chain termination. In the initiation step (initiator-derived radical primary radical), the photoinitiator (DMPA) was decomposed and underwent $\alpha$-cleavage under UV to form benzoyl and acetal radicals. Thereafter, the acetal radicals underwent fragmentation, yielding methyl radicals that acted as initiating radicals in the polymerization [27]. In this step, the free radical $\left(-\cdot \mathrm{CH}_{3}\right)$ generated by the initiator-derived primary radical was supposed to add to the double-bond of 1,4-cis isoprene. However, because of the asymmetry of the isoprene unit of ENR-25, the allyl radical was formed by allylic hydrogen abstraction through radical attack [4,28]. It can be said the methyl radical possessed the capability to abstract the hydrogen atom from the isoprene unit, resulting in the free radical, and became the free-radical donor to the monomer molecules [26]. For the chain propagation step, the chain radical of isoprene in ENR- 25 that was formed in the initiation step was grown by the successive addition of ACN monomers. It can be said that, in this step, a grafting mechanism was performed. For the chain termination, the growing radicals are terminated either by the combination (two free radicals react to each other) or by disproportionation (hydrogen of one radical in the beta position is transferred to another radical center to produce two molecules; one is saturated and the other one is unsaturated) [29]. It should be pointed out that photolysis has the ability to induce radical reactions leading to macro-radicals that create a linear, branch, and bridging crosslinking [30]. The important models of free radical grafting have been listed in Scheme 1 below.

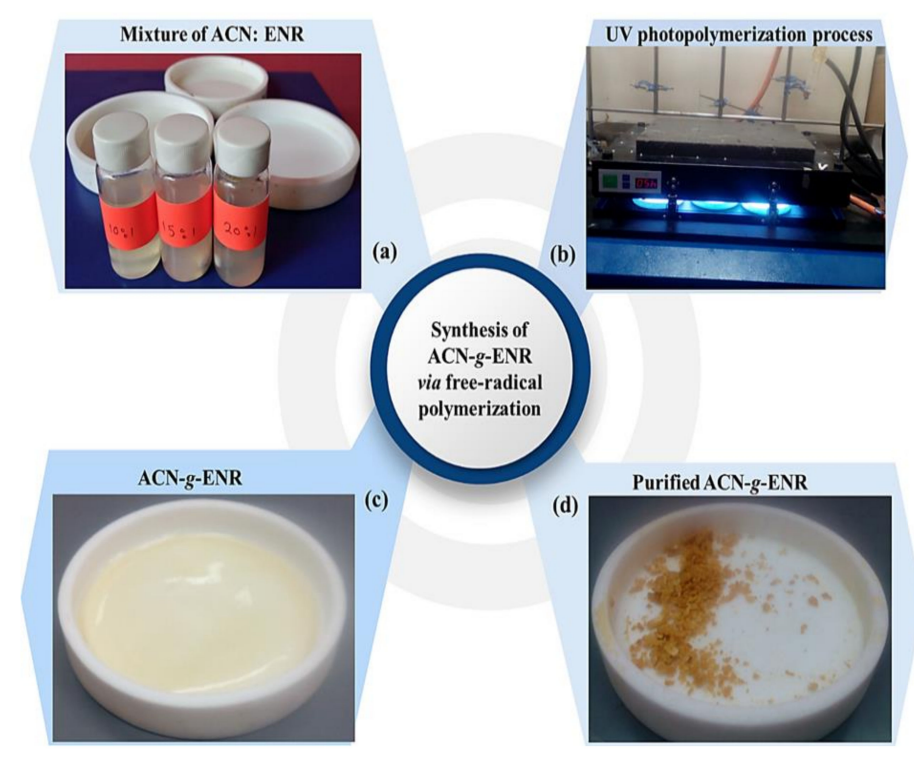

Figure 2. Synthesis of isoprene-acrylonitrile radical (ACN-g-ENR) at different mole ratios via radical photopolymerization technique: (a) Mixture of ACN: ENR, (b) UV photopolymerization process of ACN \& ENR, (c) ACN- $g$-ENR product, and (d) Purified ACN- $g$-ENR. 
(i) Chain Initiation

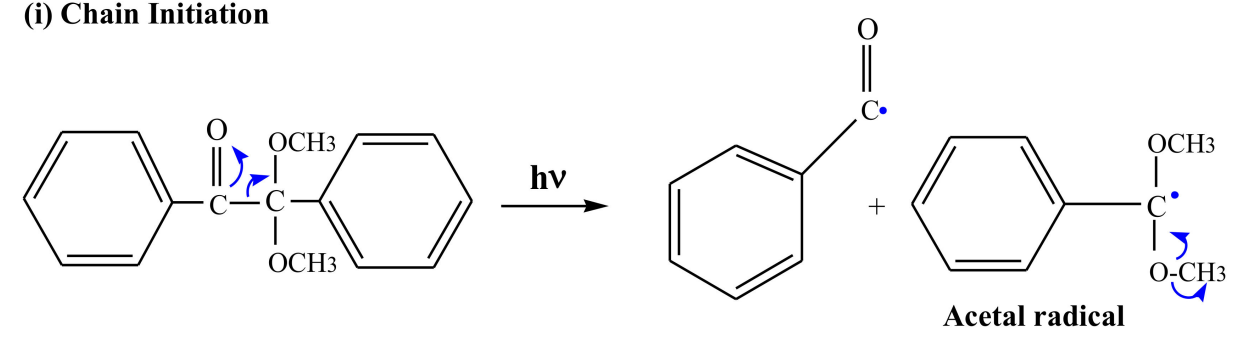

2,2-dimethoxy-2-phenyl acetophenone (DMPA) Benzoyl radical

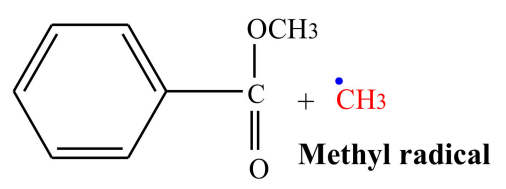

Methyl Benzoate

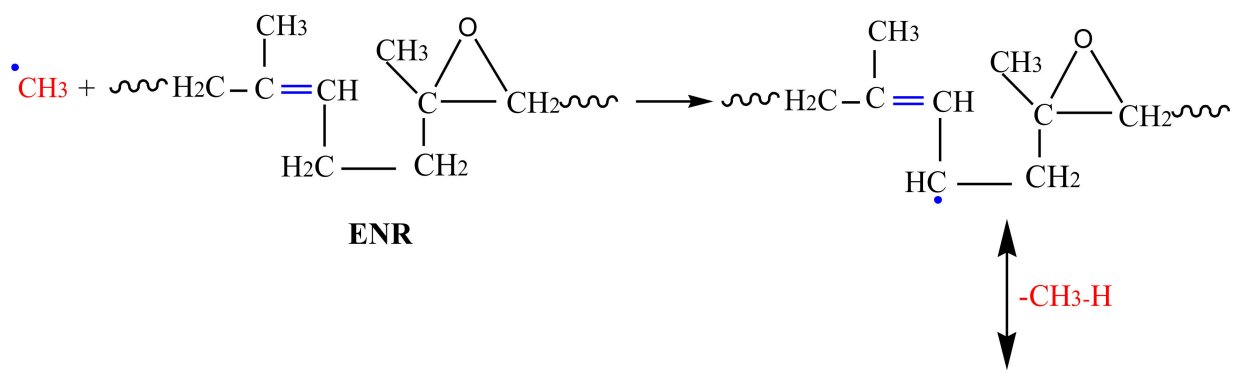

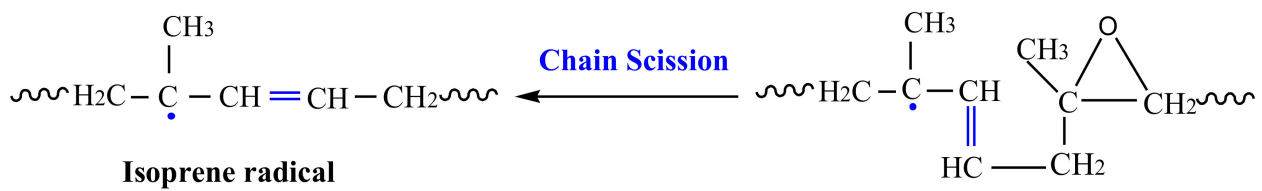

Chain Macroradical

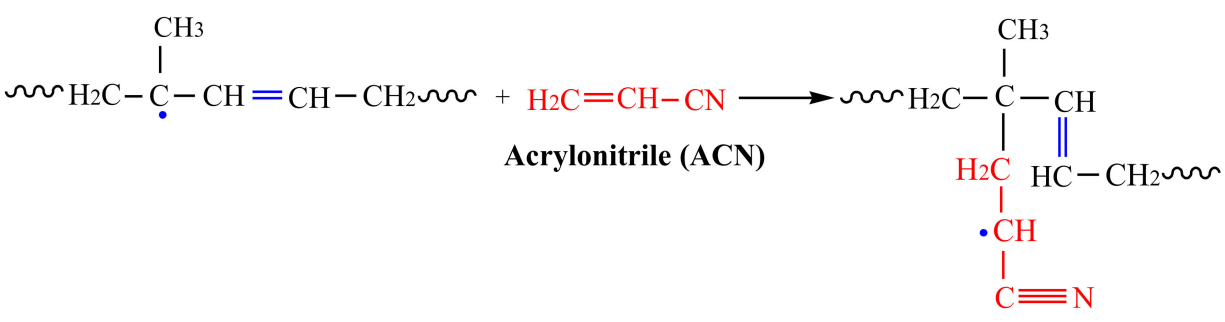

$$
\mathrm{H} 2 \mathrm{C}=\mathrm{CH}-\mathrm{CN}+\stackrel{\cdot}{\mathrm{C}} \mathrm{H}_{3} \longrightarrow \mathrm{CH}_{3}-\mathrm{CH}_{2}-\dot{\mathrm{C}} \mathrm{H}-\mathrm{CN}
$$

ACN monomer radical

Scheme 1. Cont. 
(ii) Chain Propagation

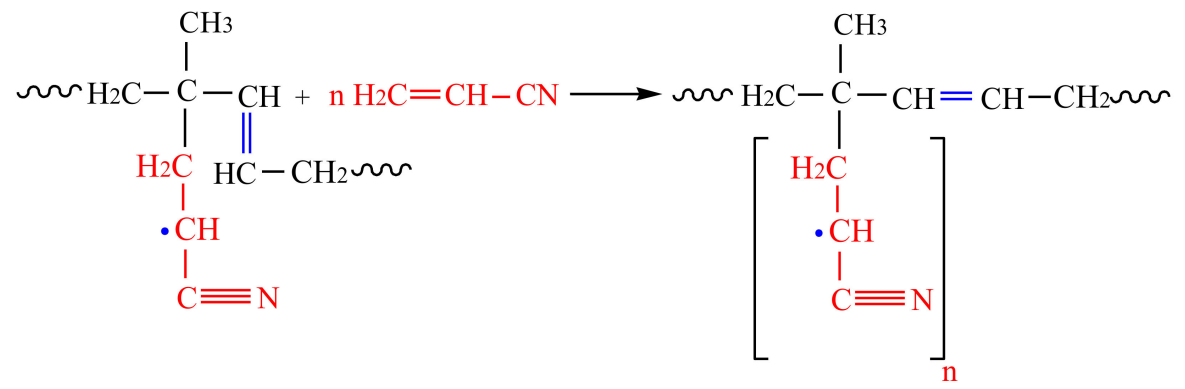

Grafted radical chain

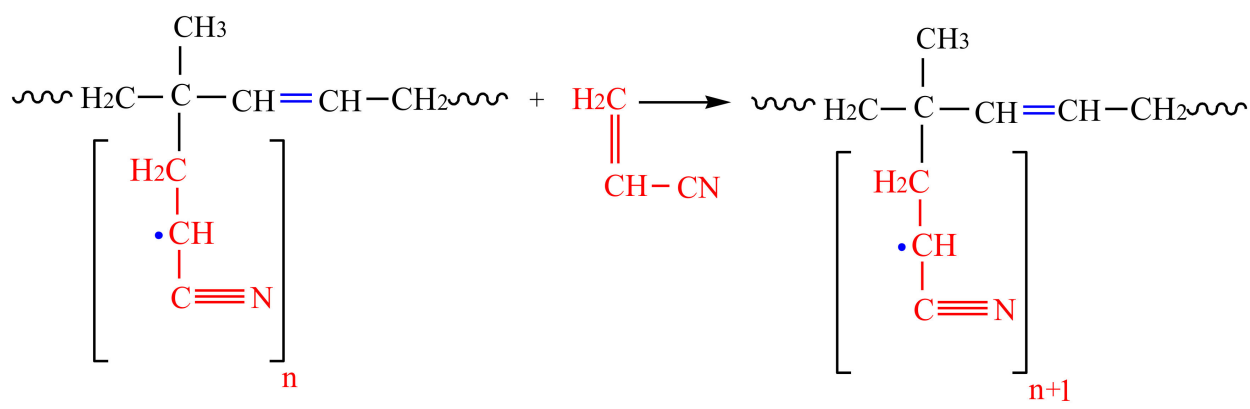$$
\mathrm{CH}_{3}-\mathrm{CH}_{2}-\dot{\mathrm{C}} \mathrm{H}-\mathrm{CN}+\mathrm{n} \mathrm{H}_{2} \mathrm{C}=\mathrm{CH}-\mathrm{CN} \longrightarrow\left[\begin{array}{c}
\mathrm{CH}_{3}-\mathrm{CH}_{2}-\mathrm{CH}-\mathrm{CN} \\
\mathrm{H}_{2}{ }_{\mathrm{CH}^{\mathrm{C}}-\mathrm{CN}}
\end{array}\right]
$$

Radical homopolymerchain

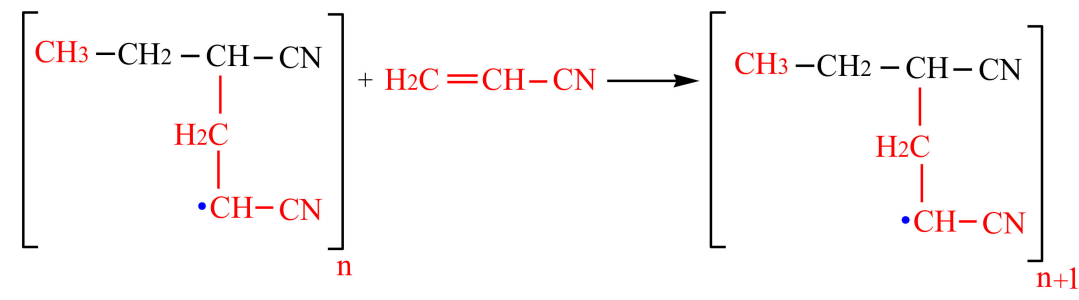

Scheme 1. Cont. 
(iii) Chain Termination

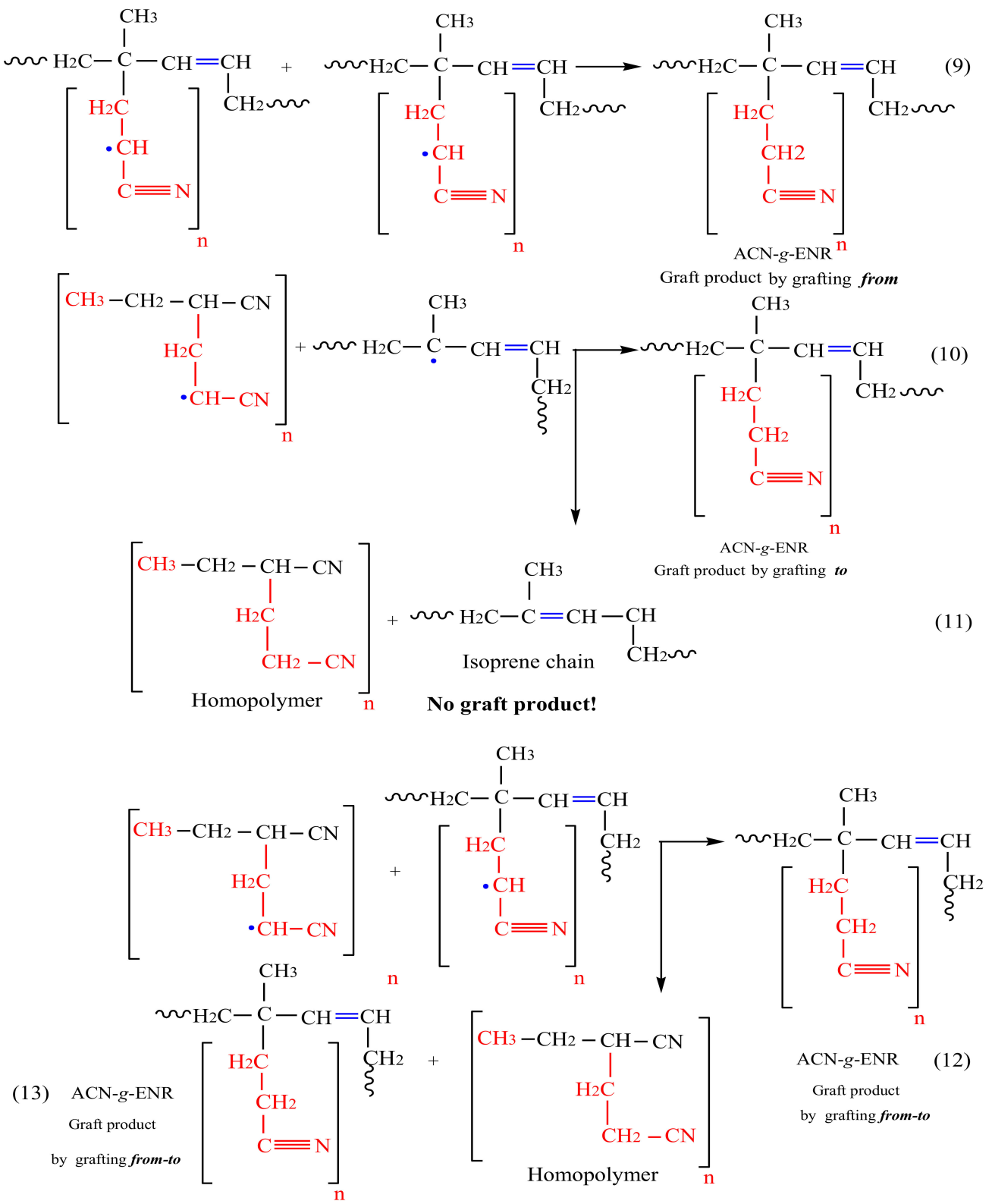

Scheme 1. Schematic of the proposed mechanism of grafting ACN onto ENR- 25 under UV photopolymerization: (i) chain initiation, (ii) chain propagation, and (iii) chain termination.

According to the underlying mechanism of grafting photopolymerization, the expected final products of the grafted polymer through the chain termination were either created from two molecules of the isoprene-acrylonitrile radical-which, in this case, is called (ACN-g-ENR) by grafting form, as shown in step 9-or from an isoprene radical with polyacrylonitrile radical —in this case, called (ACN-g-ENR)—by grafting, as shown in the steps 10 and 11. It should be noted that in the grafting, there is a possibility of producing only isoprene and homopolymer, without the graft product. There is also a possibility that the isoprene-acrylonitrile radical reacts with polyacrylonitrile radical and the expected product will be (ACN-g-ENR) or (ACN-g-ENR), accompanied by the homopolymer product. In this case, it can be said the chain termination was created by from-to, as shown in steps 12 and 13, and this will be confirmed through the results and discussion. 


\subsection{Characterizations}

\subsubsection{Fourier Transform Attenuated Total Reflection (FR-ATR)}

The chemical functional group of ACN-g-ENR samples was assessed by Perkin-Elmer Frontiers Fourier-transform-infrared (FT-IR)/far-infrared (FIR) spectrometers, incorporated with the attenuated total reflection (ATR) accessory (Waltham, MA, USA), to indicate the grafting of $\mathrm{ACN}$ onto the ENR-25 structure. The analysis was done under a wavenumber from 650 to $4000 \mathrm{~cm}^{-1}$ with a scan resolution of $2 \mathrm{~cm}^{-1}$ at room temperature.

\subsubsection{Nuclear Magnetic Resonance (NMR)}

One-dimensional (1D) (nuclear magnetic resonance $\left({ }^{1} \mathrm{H}-\mathrm{NMR}\right)$ and $\left.\left({ }^{13} \mathrm{C}-\mathrm{NMR}\right)\right)$ and two dimensional (2D) (correlated spectroscopy directly coupled neighbors (COSY) and heteronuclear multiple bond correlation (HMBC)) NMR spectra of the samples were also carried out to confirm the formation of $\mathrm{ACN}-g$-ENR and the interaction between ACN and ENR- 25. Prior to analysis, ACN-g-ENR $(30 \mathrm{mg})$ was first dissolved in deuterated dimethyl sulfoxide (DMSO- $\mathrm{d}_{6},(0.6 \mathrm{~mL})$ at $100{ }^{\circ} \mathrm{C}$ for $3 \mathrm{~h}$ until the samples were completely dissolved. 1D and 2D NMR spectroscopies were performed on a FT-NMR spectrometer Bruker/Advance III HD $400 \mathrm{MHz}$ (Bruker, Rheinstetten, Germany) at room temperature for ENR- $25(30 \mathrm{mg})$ and $\mathrm{ACN}(0.037 \mathrm{~mL})$, separately, using deuterated chloroform (CDCl3, $0.6 \mathrm{~mL})$ as a solvent.

\subsubsection{Gel Permeation Chromatography (GPC)}

The GPC technique was used by the Waters 2414 equipment with a differential refractometer index (2414) detector and Styrage ${ }^{\circledR}$ columns to record the values of average molecular weights $\left(M_{\mathrm{w}}\right)$, average molecular weights $\left(M_{\mathrm{n}}\right)$, and polydispersity index (PDI) of the ACN-g-ENR samples. A total of $5 \mathrm{mg}$ of each purified sample was solubilized in 5 $\mathrm{mL}$ THF under $60^{\circ} \mathrm{C}$ for one week to dissolve the samples completely before measurement.

\subsubsection{Grafting and Crosslinking Studies}

The grafting yield (\% GY) was calculated for the grafted products according to Equation (1) [31]

$$
\% \mathrm{GY}=C-A / A \times 100
$$

where $A$ is the weight ( $\mathrm{g}$ ) of the taken ENR-25 and $C$ is the grafted product weight. However, the grafting efficiency (\% GE) of the ACN-g-ENR sample was determined by Soxhlet instrument by extracting the boiling sample in xylene for one day. The extracted sample was dried in an oven at $50{ }^{\circ} \mathrm{C}$ until the sample reached a constant weight. \% GE was evaluated using Equation (2) [32]

$$
\% \text { GE }=\left(G_{0}-G_{1}\right) / G_{1} \times 100
$$

where $G_{0}$ and $G_{1}$ are the weight of the dried sample before and after extraction, respectively. The equilibrium swelling technique was used to calculate the crosslink density of ACN$g$-ENR products [33]. Firstly, the samples were weighed to record their initial dry weight $\left(m_{1}\right)$. Thereafter, each sample was immersed in $50 \mathrm{~mL}$ toluene at room temperature for five days to obtain the swelling equilibrium. After that, the solvent was wiped off from the sample's surfaces and the samples were then weighed to record their equilibrium weight $\left(m_{2}\right)$. The samples were dried in an oven at $50{ }^{\circ} \mathrm{C}$ for $24 \mathrm{~h}$ and reweighed to record the final dry weight $\left(m_{3}\right)$. The drying process was carried out until the sample accomplished a constant weight. The crosslink density was then evaluated according to Flory-Rehne, in Equation (3) [34].

$$
v_{e}=1 / v\left[\ln \left(1-v_{2}\right)+v_{2}+\chi v_{2}^{2}\right] / v_{2}{ }^{1 / 3}
$$

The $v_{2}$ calculated by Equation (4) and $\chi$ is the Flory-Huggins polymer-solvent interaction parameter, evaluated according to Equation (5) [34]

$$
v_{2}=m_{3} / \rho /\left[\left(m_{3} / \rho\right)+\left(m_{2}-m_{1}\right) / \rho_{s}\right]
$$




$$
\chi=v / R T\left(\delta_{1}-\delta_{2}\right)
$$

where $v_{\mathrm{e}}$ expresses information about the crosslink density (mole/volume), whereas $v$ and $v_{2}$ are the molar volume of the solvent and the volume fraction of the polymer in the swollen mass, respectively. $\rho, \rho_{\mathrm{s}}$, are the density of the polymer and solvent, respectively, $R$ is the gas constant and $T$ is the absolute temperature. $\delta_{1}$ and $\delta_{2}$ express the solubility parameter of the solvent and the polymer, respectively. However, the swelling rate was determined as in Equation (6) [35]

$$
S_{\mathrm{w}}=w_{\mathrm{g}}-w_{0} / w_{0}
$$

where $w_{0}$ and $w_{\mathrm{g}}$ are the weight of the dry and swollen samples, respectively.

\subsubsection{Dynamic Mechanical Analysis (DMA)}

DMA was implemented to demonstrate the glass transition temperatures $\left(T_{\mathrm{g}}\right)$ of the ACN-g-ENR products using the Perkin-Elmer DMA 800 dynamic mechanical analyzer (Wellesley, MA, USA) (1Hz and a maximum force amplitude of $1.5 \mathrm{~N})$. To perform this analysis, each sample was cut into approximately $25 \times 0.21 \times 5 \mathrm{~mm}^{3}$ (length $\times$ thickness $\times$ width) with a temperature range from -60 to $50{ }^{\circ} \mathrm{C}$, and the heating rate was $2{ }^{\circ} \mathrm{C} / \mathrm{min}$.

\subsubsection{Differential Scanning Calorimetry (DSC)}

DSC analysis was held by a METTLER TOLEDO ${ }^{\circledR}$ Thermal Analyzer model DSC 822e (USA) under a nitrogen flow rate of $50 \mathrm{~mL} \mathrm{~min}^{-1}$. Approximately $\sim 3-5 \mathrm{mg}$ of each sample was weighed and subjected to two heating-cooling cycles at a heating rate of $10{ }^{\circ} \mathrm{C} \mathrm{min}-1$ and a temperature range from -100 to $250{ }^{\circ} \mathrm{C}$ to study the thermal transitions of the prepared products.

\subsubsection{Thermogravimetry Analysis (TGA) and Derivation of Thermogravimetric (DTG) Analyses}

TGA and DTG were performed to study the degradation temperature, mass loss, and thermal stability, as well as the compositional information, of ACN-g-ENR samples. TGA was carried out under the Setaram LABSYS EVO simultaneous thermal analyzer (Caluire-et-Cuire, France). The samples for TGA and DTG were carefully weighed in a range between $\sim 7$ and $9 \mathrm{mg}$ in an aluminum crucible put in the center of the heating chamber. TGA was carried out in an inert environment under a nitrogen atmosphere with a temperature range from 30 to $600{ }^{\circ} \mathrm{C}$ and a heating rate of $10{ }^{\circ} \mathrm{C} \mathrm{min}-1$. The raw data were analyzed by the Calisto software TGA program.

\subsubsection{Dielectric Spectroscopy Study (DSS)}

Dielectric spectroscopy (DS), an analog to the DMA test, is a classical tool adopted in order to study the dielectric behavior and relaxation process of the prepared samples. Study of the dielectric properties of the grafted ACN on an ENR structure was carried out using an impedance analyzer that allows the complex electrical magnitudes to be quantified as the impedance $Z^{*}(\omega)$, conductivity $\sigma^{*}(\omega)$, and dielectric permittivity $\varepsilon^{*}(\omega)$. This technique is based on the measurement and subsequent evaluation of some frequency-dependent parameters, including, in particular, the complex, effective permittivity $\varepsilon^{*}(\omega)$

$$
\varepsilon^{*}(\omega)=\varepsilon^{\prime}(\omega)-j \varepsilon^{\prime \prime}(\omega)
$$

where $\omega$ is the angular frequency and $\omega=2 \pi f, j^{2}=-1$ is the imaginary constant, and $\varepsilon^{\prime}$ and $\varepsilon^{\prime \prime}$ are the real and imaginary components of the complex permittivity that, respectively, regard the degree of polarization and loss mechanisms in the form of heat energy in response to an applied variable electric field. In addition, $\varepsilon^{\prime}$ and $\varepsilon^{\prime \prime}$ are proportional to the energy stored or dissipation per period, respectively, in the materials. $\varepsilon^{\prime}$ and $\varepsilon^{\prime \prime}$ are also called dielectric constant and dielectric loss. Moreover, the tangent of the phase angle 
between applied voltage and resulting currents, also termed the dissipation factor, results from [5]

$$
\tan \delta=\varepsilon^{\prime \prime} / \varepsilon^{\prime}
$$

where $\tan \delta$ is a factor that that provides information on the loss of energy and is highly based on the physical conditions of the insulating material. T The relaxation time, $\tau$ can be calculated from Equation (9) by using the maximum frequency, $f_{\mathrm{m}}$ value obtained from the graph of $\tan \delta$ versus frequency) [36]

$$
\omega \times \tau=2 \pi f_{\mathrm{m}} \times \tau=1
$$

where $\omega$ express the angular frequency of the applied field and $\tau$ is Debye relaxation time. In this work, DSS measurements were performed via electrochemical impedance spectroscopy (EIS) with a single-channel VersaSTAT4 Schlumberger Instrument (Berwyn, PA, USA). The samples for DSS measurements were films of approximately 16-18 $\mathrm{mm}$ in thickness, pre-pared by in-suit UV curing. The samples were subjected to the frequency region $(0.1 \mathrm{~Hz}-1 \mathrm{MHz})$ of $100 \mathrm{mV}$ amplitude and room temperature. Each film, after being cut into a circular shape, was sandwiched between two identical stainless-steel ion blocking electrodes with a surface contact area of $1.76 \mathrm{~cm}^{2}$ after calculating the average thickness between them $(0.016-0.018 \mathrm{~cm})$. From the impedance data, the real and imaginary permittivity, respectively, $\left(\varepsilon_{\mathrm{r}}\right),\left(\varepsilon_{\mathrm{i}}\right)$, real electrical modulus $\left(M_{\mathrm{r}}\right)$, imaginary electrical modulus $\left(M_{\mathrm{i}}\right)$, dielectric loss tangent $(\tan \delta)$, and relaxation time $(\tau)$ for ACN-g-ENR samples were evaluated according to the equations reported by Woo et al. [36] and Basri et al. [37].

\section{Results and Discussion}

\subsection{Chemical interaction}

FTIR was performed to identify the constituent interaction of ACN onto ENR- 25. The absorbance peaks at 2962, 2924, and $2855 \mathrm{~cm}^{-1}$ in (Figure 3a), which refer to $-\mathrm{CH}$ symmetric stretching $\left(v_{\mathrm{s}}-\mathrm{CH}_{3}\right),-\mathrm{CH}$ asymmetric stretching $\left(v_{\mathrm{as}}-\mathrm{CH}_{2}\right)$, and $-\mathrm{CH}$ symmetric stretching $\left(v_{\mathrm{s}}-\mathrm{CH}_{2}\right)$ in the ENR- 25 structure, were not noticeably affected after grafting.

It can be noticed in the FTIR spectra below (Figure $3 \mathrm{~b}$ ) that all products showed an additional peak at $2242 \mathrm{~cm}^{-1}$. This peak is owing to the stretching vibrations of $-\mathrm{C} \equiv \mathrm{N}$, which consider the main functional group in the ACN structure. Besides, the peak in the $-\mathrm{C} \equiv \mathrm{N}$ stretching was of medium intensity and observed at $2230 \mathrm{~cm}^{-1}$ for ACN corroborates with the grafted ENR-25 samples at $2242 \mathrm{~cm}^{-1}$. Compared with ENR- 25, the existence of this peak proves that the grafting of ACN occurred successfully onto the ENR- 25 backbone. It should be pointed out the $-C=C$ - stretching in ENR- 25 at $1664 \mathrm{~cm}^{-1}$ was shifted to a high wavenumber after grafting. This indicated that the chain initiation within the proposed mechanism was carried out via free radical allylic hydrogen not an addition to vinyl group $-\mathrm{C}=\mathrm{C}-$, as shown in Scheme 1, step 2. Furthermore, three new peaks were observed at 1710, 1717 , and $1723 \mathrm{~cm}^{-1}$ for $\mathrm{ACN}_{10}-g-\mathrm{ENR}_{1}, \mathrm{ACN}_{15}-g-\mathrm{ENR}_{1}$, and $\mathrm{ACN}_{20}-g-\mathrm{ENR}_{1}$, respectively. This is attributed to the double bond in $-\mathrm{C}=\mathrm{N}$ stretch as a result of resonance in $\mathrm{ACN}$ monomer [38], which appeared at 1713 and $1728 \mathrm{~cm}^{-1}$ for ACN and PAN, respectively. It can be deduced that the grafting was achieved by grafting from-to, as shown in (Scheme 1, Step 13).

It should be pointed out that in-plane bending (scissoring) $\left(\delta_{\mathrm{s}}-\mathrm{CH}_{2}\right)$ and out-of-plane bending (wagging) $\left(\omega-\mathrm{CH}_{2}\right)$ in (Figure 3c) were shifted to lower wavenumbers of 1447 and $1377 \mathrm{~cm}^{-1}$, respectively, for all grafted samples compared to ENR- 25, ACN, and PAN. The in-plane bending (rocking) $\left(\rho-\mathrm{CH}_{2}\right)$ in (Figure 3d), was found at 751 and $753 \mathrm{~cm}^{-1}$ for $\mathrm{ACN}_{15}-g-\mathrm{ENR}_{1}$ and $\mathrm{ACN}_{20}-g-\mathrm{ENR}_{1}$, respectively. This indicates that there is a change in the ENR- 25 structure after grafting. Moreover, the FTIR spectra revealed that the absorption peak at $835 \mathrm{~cm}^{-1}$, belonging to $=\mathrm{C}-\mathrm{H}$ wagging, shifted to a lower wavenumber of $\sim 832 \mathrm{~cm}^{-1}$ for all grafted products. This is a result of the involvement of double bonds during the chain scission, [4] as shown in the proposed mechanism (Scheme 1, step 2), and will be explained in the GPC section. 

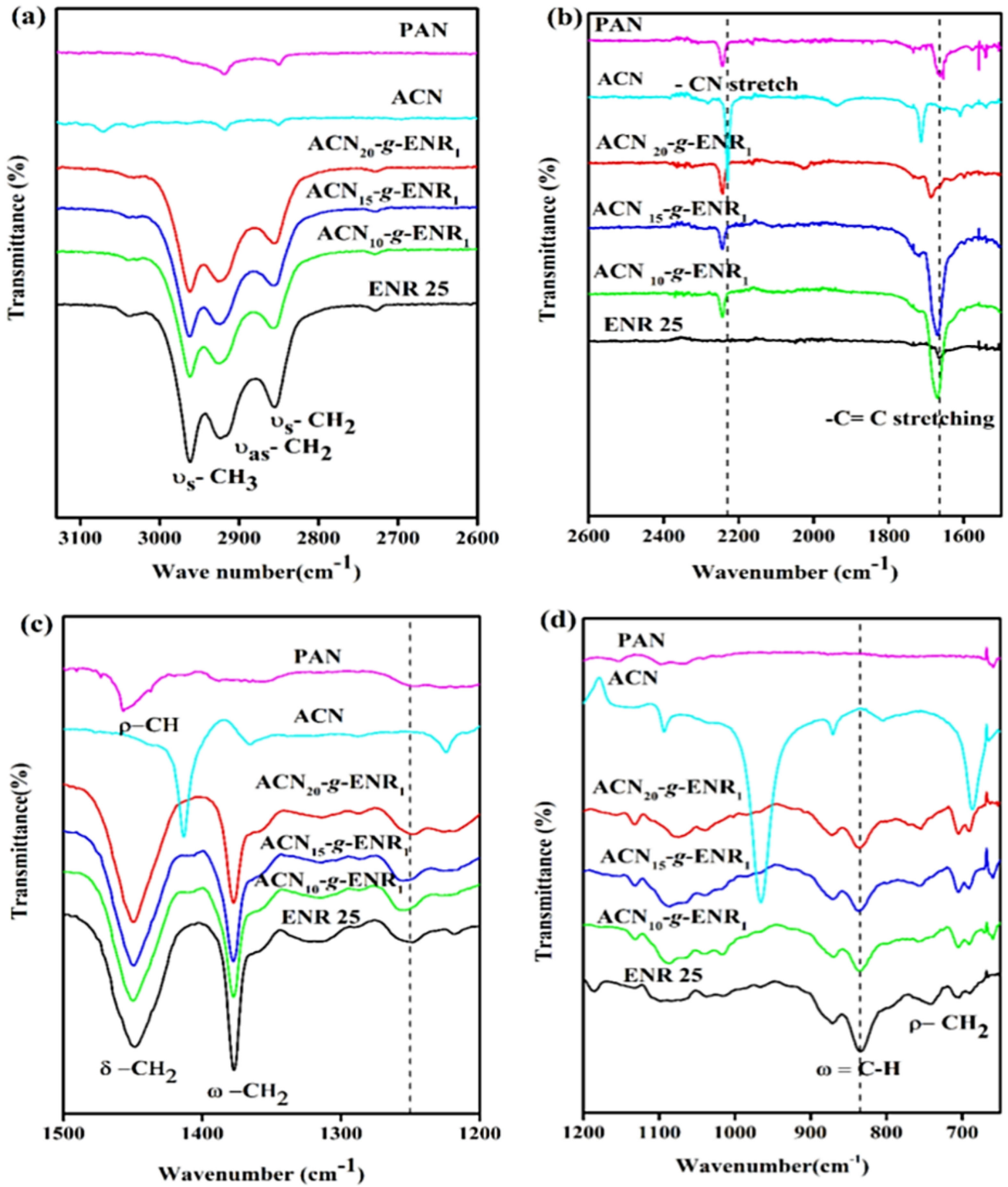

Figure 3. FTIR of ENR- 25, ACN, polyacrylonitrile (PAN), and ACN-g-ENR products at different mole ratios. (a) $-\mathrm{CH}$ stretching (b) $-\mathrm{C} \equiv \mathrm{N}$ vibrations and $-\mathrm{C}=\mathrm{C}$ - stretching (c) $-\mathrm{CH}_{2}$ in -plane, outplane regions, and (d) $-\mathrm{CH}_{2},-\mathrm{CH}$ in -plane, out-plane regions, and epoxy ring stretching.

It should also be noted that the oxirane ring at $870 \mathrm{~cm}^{-1}$ for ENR- 25 does not exhibit any substantial change, which implies that the oxirane group was not included in the chain scission reaction [4]. This indicated the grafting of ACN onto ENR- 25 successfully occurred on $-\mathrm{C}=\mathrm{C}-$ in the rubber chain instead of the oxirane ring. The analyses below also indicate the formation of grafting of ACN onto the ENR-25 backbone. Supplementary Information Table S1 shows the FTIR's wavenumber assignments of ENR- 25, ACN, PAN, and $\mathrm{ACN}-g$-ENR products at different mole ratios.

1D and 2D NMRs were carried out to test the structure of ENR- 25 after the reaction with ACN and confirm the chemical interaction between ACN and ENR- 25. 1D NMR spectra for $\mathrm{ACN}, \mathrm{PAN}$, and $\mathrm{ACN}_{10^{-}}-\mathrm{E}-\mathrm{ENR}_{1}$, and $\mathrm{ACN}_{20}-g$-ENR 1 are presented in Supplementary Information Figure S2, and 2D NMR spectra of PAN and $\mathrm{ACN}_{10}-g-\mathrm{ENR}_{1}$, and $\mathrm{ACN}_{20}-\mathrm{g}-\mathrm{ENR}_{1}$ are given in Supplementary Information Figure S3. The ${ }^{1} \mathrm{H}-\mathrm{NMR}$ of the purified ENR- $25\left(400 \mathrm{MHz}, \mathrm{CDCl}_{3}, \delta\right.$ (ppm)) in (Figure 4a) exhibited signals similar to the previous studies [39,40]: $\delta 1.29 \mathrm{ppm}\left(-\mathrm{CH}_{2}-\mathrm{CH}_{3} \mathrm{COCH}\right), \delta 1.57 \mathrm{ppm}\left(\mathrm{CH}_{2}-\mathrm{CH}_{3} \mathrm{CO}\right), \delta 1.70$ ppm $\left(-\mathrm{CH}_{2}-\mathrm{CH}_{3} \mathrm{C}=\mathrm{CH}\right), \delta 2.20 \mathrm{ppm}\left(-\mathrm{CH}_{3} \mathrm{C}=\mathrm{CH}-\mathrm{CH}_{2}\right), \delta 2.06 \mathrm{ppm}\left(-\mathrm{CH}_{3} \mathrm{COCH}-\mathrm{CH}_{2}-\right)$, 
$\delta 2.72 \mathrm{ppm}\left(-\mathrm{CH}_{3} \mathrm{COCH}-\right), \delta 5.17 \mathrm{ppm}\left(-\mathrm{CH}_{3} \mathrm{C}=\mathrm{CH}-\right)$, and $\delta 7.27 \mathrm{ppm}$ (the residual of $\mathrm{CDCl}_{3}$ solvent).

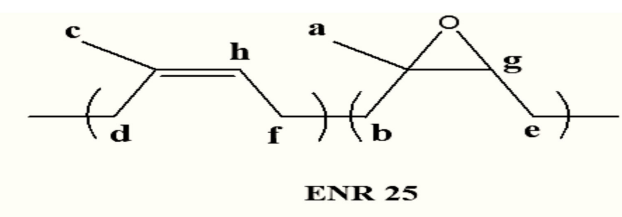

(a) ${ }^{1}$ H-NMR ENR 25

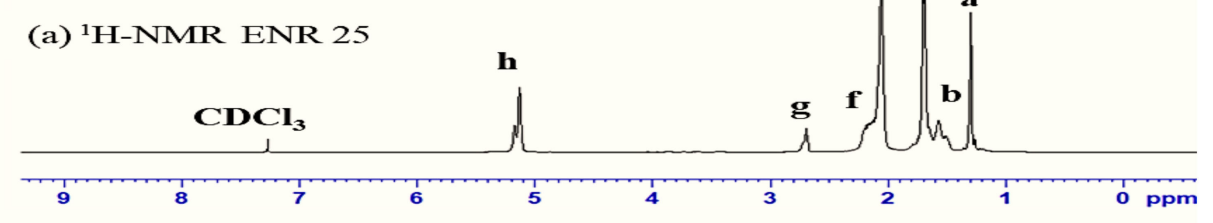

(b) ${ }^{1} \mathrm{H}-\mathrm{NMR}$ ACN15-g-ENR1
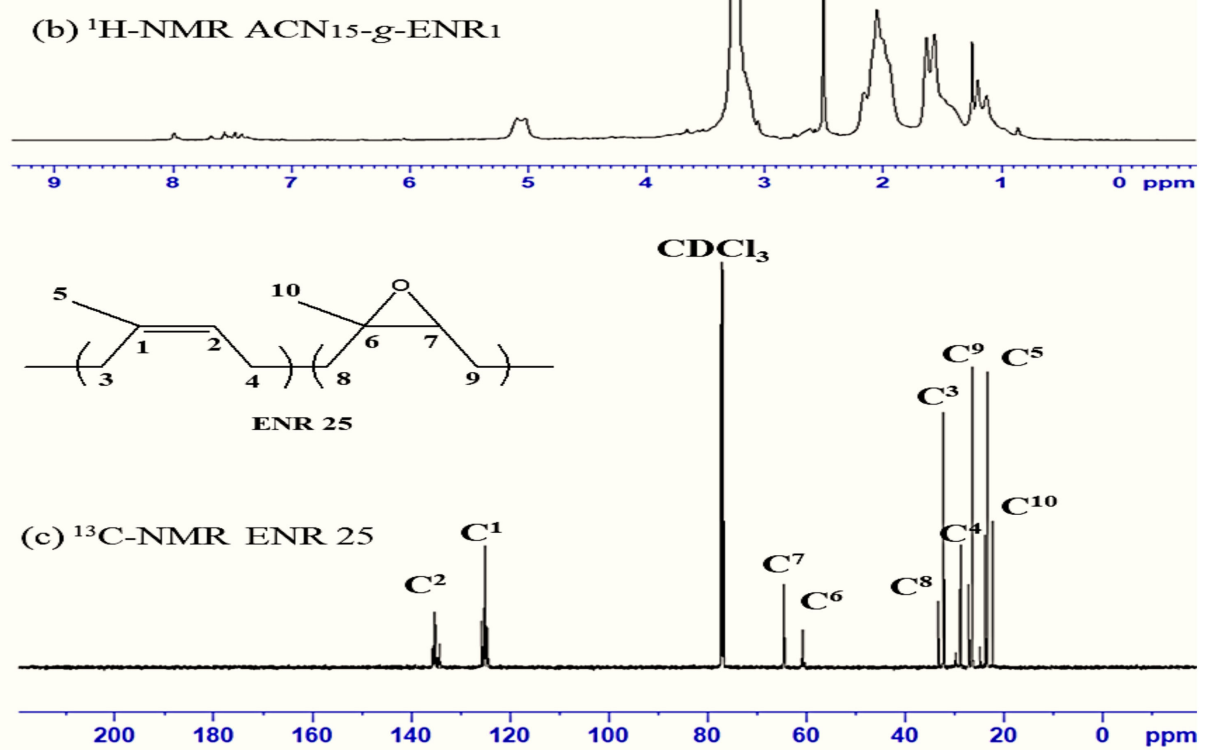

(d) ${ }^{13} \mathrm{C}-\mathrm{NMR}$ ACN15-g-ENR1

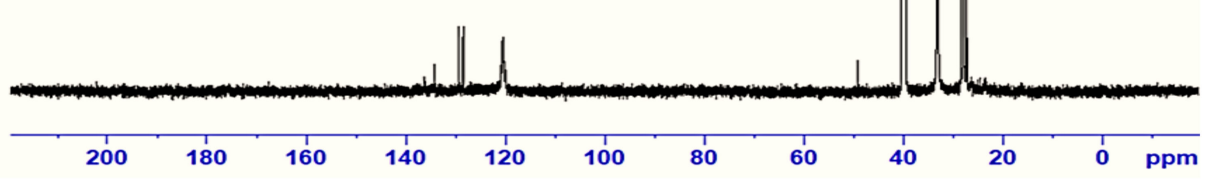

Figure 4. 1D NMR spectra for ENR 25 and $\mathrm{ACN}_{15}-g$-ENR ${ }_{1}$. (a) ${ }^{1} \mathrm{H}-\mathrm{NMR}$ of ENR 25, (b) ${ }^{1} \mathrm{H}-\mathrm{NMR}$ $\mathrm{ACN}_{15}$-g-ENR 1, (c) ${ }^{13} \mathrm{C}-\mathrm{NMR}$ of ENR 25, and (d) ${ }^{13} \mathrm{C}-\mathrm{NMR}$ of $\mathrm{ACN}_{15}-\mathrm{g}$-ENR ${ }_{1}$. 
Figure 4a shows that the ${ }^{1} \mathrm{H}-\mathrm{NMR}$ chemical shift at $\delta 1.29 \mathrm{ppm}$ is assigned to the methyl protons bound to the epoxidized isoprene unit, the shift at $\delta 2.72 \mathrm{ppm}$ to the methine protons of the epoxidized isoprene unit, and the shift at $\delta 1.57$ and $\delta 2.06 \mathrm{ppm}$ to the methylene protons that bound to the epoxidized isoprene unit. However, the chemical shifts observed at $\delta 1.70, \delta 2.20$, and $\delta 5.17 \mathrm{ppm}$ represent the methyl, methylene (allylic proton), and methine (vinylic proton) bonded to the isoprene unit. The methylene protons as shown in the structure $\left(-\mathrm{CH}_{2}-\mathrm{CH}_{3} \mathrm{C}=\mathrm{CH}\right)$ were overlapped with the methylene protons bonded to the epoxidized isoprene unit. The overlapping signal may be attributed to the methylene protons of the ENR-25 chain [40]. Figure $4 \mathrm{~b}$ and Figure S2 show the ${ }^{1} \mathrm{H}-\mathrm{NMR}$ $\left(400 \mathrm{MHz}, \mathrm{DMSO}-\mathrm{d}_{6}, \delta(\mathrm{ppm})\right.$ ) for all samples of ACN-g-ENR. It was observed that the olefinic methine proton at $5.17 \mathrm{ppm}$ did not disappear after grafting. Besides this, a signal at $\delta 2.20 \mathrm{ppm}$ was assigned to the hydrogen allylic group at position $\mathbf{b}$, as shown in the structure ENR 25 in ${ }^{1} \mathrm{H}-\mathrm{NMR}$ spectrum. This indicates that chain initiation was carried out via free radical allylic hydrogen, as shown in the proposed mechanism and discussed earlier. Furthermore, the signal at $1.30 \mathrm{ppm}$ was not affected after grafting. As such, it can be deduced that the grafting of ACN onto the backbone ENR-25 did not occur via the ring-opening reaction of the protonated epoxidized ring, and also the oxirane group was not included in the chain scission reaction [4]. Additional signals appeared within $\delta 1.5$ and $\delta 3.16-3.39 \mathrm{ppm}$, related to $\left(-\mathrm{CH}_{2}-\mathrm{CH}-\mathrm{CN}\right)$, respectively. This proves that $\mathrm{ACN}$ was grafted on the ENR backbone. It should be noted that protons of ACN are assigned at $\delta$ 5.7-6.3 ppm, as shown in Supplementary Information Figure S2. However, the vinyl group disappeared when the ACN converted to the monomer radical. In addition, this signal also appeared in ${ }^{1} \mathrm{HNMR}$ of the PAN spectrum in Figure S2. It can be said that the grafting was achieved by grafting from-to, in step 13. In addition, it was observed that the chemical shift in $-\mathrm{CH}_{3}$ and $-\mathrm{CH}_{2}$ bound to an isoprene unit shifted to a lower chemical shift due to the change in the structure of ENR after grafting.

The ${ }^{13} \mathrm{C}-\mathrm{NMR}$ spectrum of the purified ENR-25 $\left(400 \mathrm{MHz}, \mathrm{CDCl}_{3}, \delta(\mathrm{ppm})\right)$ above is shown in (Figure 4c). The signals within $\delta 22.3$ and $33.2 \mathrm{ppm}$ represent methyl carbons at $\mathrm{C}^{5}$ and $C^{10}$ and the doublets of methylene carbons of $C^{3}, C^{4}, C^{8}$ and $C^{9}$. The signals at 60 and $64 \mathrm{ppm}$ represent carbons of the epoxy ring $\mathrm{C}^{6}$ and $\mathrm{C}^{7}$, respectively. The signal at $77 \mathrm{ppm}$ is assigned to the residual solvent of $\mathrm{CDCl}_{3}$, and $125.2 \mathrm{ppm}$ and 135.6 are represented by $C^{1}$ and $C^{2}$ from the isoprene unit, respectively. It should be pointed out that the methylene carbons of $C^{4}$ and $C^{9}$ were located in the lower frequency region (upfield) compared to the methylene carbons of $C^{3}$ and $C^{8}$. This is owing to the methine carbons of $C^{2}$ and $C^{7}$ that, respective to the vicinal methylene carbons of $C^{4}$ and $C^{9}$, have greater electron density compared to the quaternary carbons of $\mathrm{C}^{1}$ and $\mathrm{C}^{6}$, respective to the vicinal methylene carbons of $\mathrm{C}^{3}$ and $\mathrm{C}^{8}$. Therefore, they shielded the methylene carbons $\mathrm{C}^{4}$ and $\mathrm{C}^{9}$ more [40]. The spectrums of ${ }^{13} \mathrm{C}-\mathrm{NMR}\left(400 \mathrm{MHz}, \mathrm{CDCl}_{3}, \delta(\mathrm{ppm})\right.$ ) for ACN and $\left(400 \mathrm{MHz}, \mathrm{DMSO}-\mathrm{d}_{6}\right.$, $\delta(\mathrm{ppm}))$ for PAN in Supplementary Information Figure S2 show signals at $116 \mathrm{ppm}$ for $A C N$ and 119 ppm for PAN. These signals are ascribed to $(-C \equiv N)$ and appeared in all ratios of ACN- $g$-ENR in Figure $4 \mathrm{~d}$ and Figure S2. Moreover, the signal at $\delta 125-136 \mathrm{ppm}$ for $(-\mathrm{C}=\mathrm{C}-)$ shifted to a lower chemical shift, ascribed to the change in the structure after grafting. Besides, the chemical shift at $C^{\text {at }}, C^{7}$, and $C^{10}$ did not detect after grafting. This indicates that the oxirane ring was not included in the chain scission. The signals between $\delta$ 20 and $40 \mathrm{ppm}$ are related to the carbons of $\left(-\mathrm{CH}_{2}\right.$ and $\left.-\mathrm{CH}\right)$ in the PAN structure; however, the signal at $\delta 40 \mathrm{ppm}$ is related to the residual of DMSO- $\mathrm{d}_{6}$.

2D NMR was done to study the correlation of ${ }^{1} \mathrm{H}-{ }^{1} \mathrm{H}$ and ${ }^{1} \mathrm{H}-{ }^{13} \mathrm{C}$ after grafting of $\mathrm{ACN}$ onto the ENR- 25 structure. The COSY spectrum of ENR- 25 in (Figure 5a) shows that the methine proton of isoprene $C^{2}$ at $\delta 5.17 \mathrm{ppm}$ was clearly correlated to the signal at $\delta 2.20$ ppm (the methylene protons, $\mathrm{C}^{4}$ ) and the signal at $\delta 1.70 \mathrm{ppm}$ of the methyl group through allylic (four-bonds). However, the spectrum of the grafted sample in (Figure 5b) shows only the signal at $\delta 1.9-3.2 \mathrm{ppm}$, related to ACN protons. For the HMBC spectrum in Figure $5 \mathrm{c}, \mathrm{d}$, it was observed in the ENR- 25 spectrum, as reported by Hamzah et al. [40], that the signal at $\delta 5.17 \mathrm{ppm}$ correlates to $\left(\mathrm{C}^{3}, \mathrm{C}^{4}\right.$, and $\left.\mathrm{C}^{5}\right)$, the signal at $\delta 1.30 \mathrm{ppm}$ correlates to 
$\left(\mathrm{C}^{7}\right.$ and $\left.\mathrm{C}^{8}\right)$, at $\delta 1.70 \mathrm{pm}$ correlates to $\left(\mathrm{C}^{2}\right.$ and $\left.\mathrm{C}^{3}\right)$, the signal at $\delta 1.57 \mathrm{ppm}$ correlates to $\left(\mathrm{C}^{6}\right.$, $\mathrm{C}^{7}$, and $\left.\mathrm{C}^{10}\right)$, the signal at $\delta 2.06 \mathrm{ppm}$ correlates to $\left(\mathrm{C}^{6}\right.$ and $\left.\mathrm{C}^{7}\right)$, the signal at $\delta 2.20 \mathrm{ppm}$ correlates to $\left(\mathrm{C}^{1}\right.$ and $\left.\mathrm{C}^{2}\right)$, the signal at $\delta 2.72 \mathrm{ppm}$ correlates to $\left(\mathrm{C}^{8}, \mathrm{C}^{9}\right.$, and $\left.\mathrm{C}^{10}\right)$, and that at $\mathrm{H}$, belonging to $\mathrm{C}^{3}$, correlates to $\left(\mathrm{C}^{1}, \mathrm{C}^{2}\right.$, and $\left.\mathrm{C}^{5}\right)$. However, all $\mathrm{ACN}-\mathrm{g}$-ENR samples exhibit a new signal at $\delta 1.9$ and $\delta 3.1 \mathrm{ppm}$, correlating to $C$ at $\delta 120 \mathrm{ppm}$.
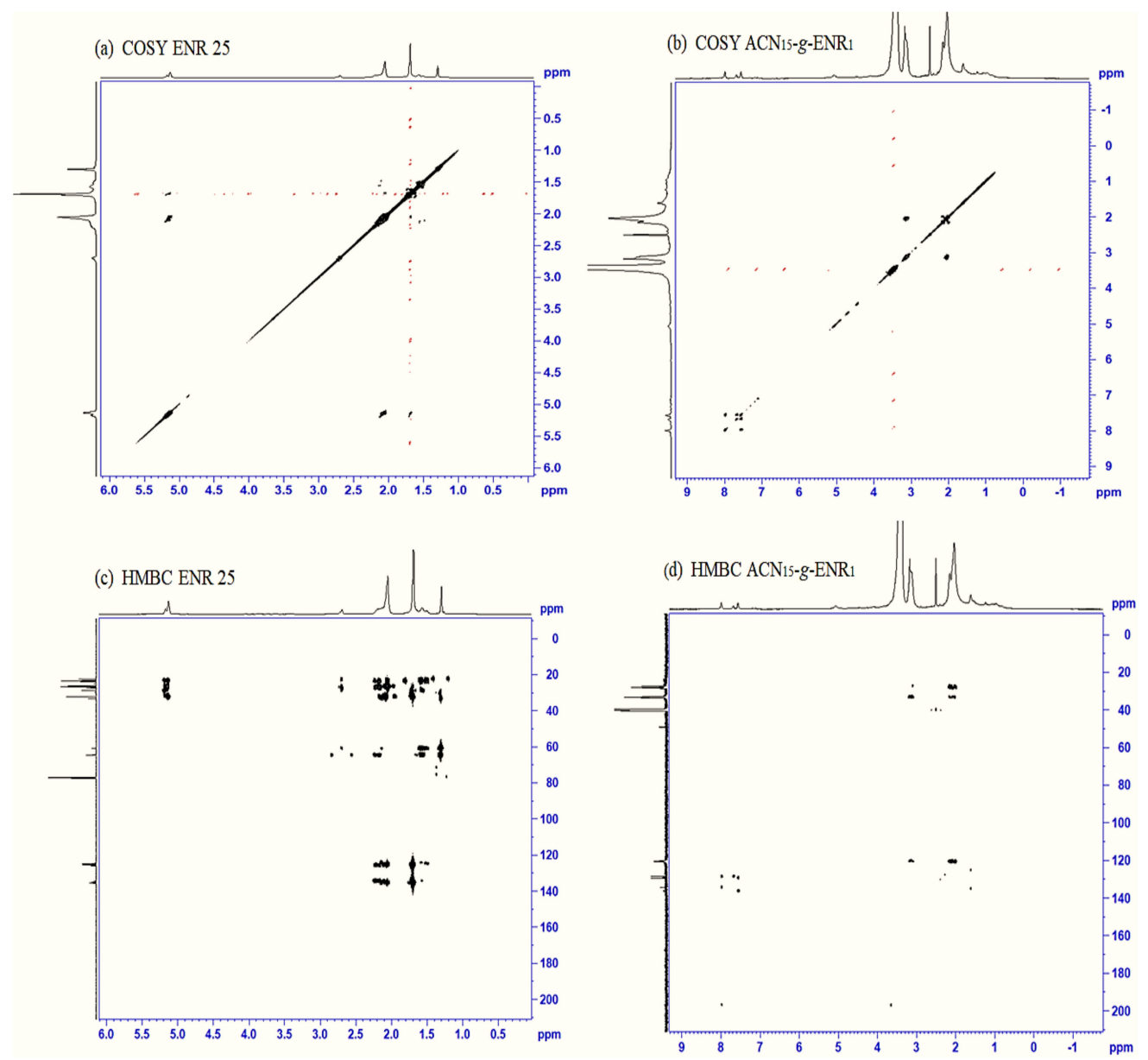

Figure 5. 2D NMR spectra for ENR- 25 and $\mathrm{ACN}_{15}$-g-ENR 1 : (a) COSY of ENR 25, (b) COSY ACN $15^{-}$ g-ENR 1 , (c) $\mathrm{HMBC}$ of ENR 25, and (d) $\mathrm{HMBC}$ of $\mathrm{ACN}_{15}-\mathrm{g}-\mathrm{ENR}_{1}$.

\subsection{Molecular Weight Distribution Measurements (MWDM)}

GPC was carried out to determine the values of the average molecular weights $\left(M_{\mathrm{W}}\right)$, number average molecular weights $\left(M_{\mathrm{n}}\right)$, and polydispersity index (PDI) of the grafted products, as shown in Table 1 below. The values of $M_{\mathrm{w}}$ for the purified ENR-25, liquid epoxidized natural rubber (LENR 25), and PAN (under UV as control samples) were recorded at $\sim 1287,538, \sim 51,540$, and $\sim 77,601 \mathrm{~g} \mathrm{~mole}^{-1}$, respectively. However, it was found that the value of $M_{\mathrm{W}}$ was decreased to $\sim 171,064, \sim 114,657$, and $\sim 252,786 \mathrm{~g} \mathrm{~mole}^{-1}$ for $\mathrm{ACN}_{10}-g-\mathrm{ENR}_{1}, \mathrm{ACN}_{15}-g-\mathrm{ENR}_{1}$, and $\mathrm{ACN}_{20}-g-\mathrm{ENR}_{1}$, respectively, compared to the purified ENR- 25. This decrease is due to the degradation of ENR-25 under UV, which contributed to the decrease in the $M_{\mathrm{w}}$, as reported by Rooshenass et al. [4], Lee et al. [10], and Rahman et al., [11,12]. In addition, it can be deduced that the ENR-25 was degraded by looking at LENR as a control sample; it was observed that the $M_{\mathrm{W}}$ decreased under UV compared to ENR-25. Moreover, the decrease in $M_{\mathrm{W}}$ is due to the chain scission of ENR-25, as shown in Scheme 1, step 2 and step 13 when ACN created a radical molecule that induced the macromolecular to produce chain scission. As a result, the underlining mechanism of the grafting process can be said to have been carried out by the from-to mechanism, as shown in (Scheme 1, step 13). 
Table 1. Gel permeation chromatography data for PAN, LENR 25, ENR- 25, and ACN-g-ENR products at various mole ratios.

\begin{tabular}{|c|c|c|c|}
\hline Sample ID & $M_{\mathrm{n}}\left(\mathrm{g} \mathrm{mole}^{-1}\right)$ & $M_{\mathrm{w}}\left(\mathrm{g} \mathrm{mole}^{-1}\right)$ & PDI $\left(M_{\mathrm{w}} / M_{\mathrm{n}}\right)$ \\
\hline Non-purified ENR- 25 & 990,872 & $2,460.391$ & 2.48 \\
\hline Purified ENR- 25 & 178,792 & $1,287.538$ & 7.20 \\
\hline LENR 25 (as control) & 8442 & 51,540 & 6.11 \\
\hline * PAN (Typical) & $\mathrm{N} / \mathrm{A}$ & 150,000 & $\mathrm{~N} / \mathrm{A}$ \\
\hline PAN (as control) & 15,697 & 77,601 & 4.94 \\
\hline $\mathrm{ACN}_{10}-g-\mathrm{ENR}_{1}$ & 50,408 & 171,064 & 3.39 \\
\hline $\mathrm{ACN}_{15}-g-\mathrm{ENR}_{1}$ & 11,286 & 114,657 & 10.16 \\
\hline $\mathrm{ACN}_{20}-g-\mathrm{ENR}_{1}$ & 33,547 & 252,786 & 7.54 \\
\hline
\end{tabular}

* Standard according to Sigma-Aldrich.

Although no unique relation was found by Azizi et al. [41] for the variation in grafting and cross-linking performance as a function of the MWDM, they have reported increasing the grafting level and gel content with increasing the values of $M_{n}$ and $M_{w}$ increased. This is owing to several long chains that are present in the synthesized polymer. Contrary, in this work, the lowest $\mathrm{M}_{\mathrm{w}}$ obtained the highest grafting. Furthermore, the highest $\mathrm{Mw}$ was obtained in $\mathrm{ACN}_{20}-g-\mathrm{ENR}_{1}$ compared to the other mole ratios. This is ascribed to the grafting in this ratio, which has led to increasing the chain length rather than increasing the reaction site [42]. However, $\mathrm{ACN}_{15}-g-\mathrm{ENR}_{1}$ was given the lowest $\mathrm{M}_{\mathrm{W}}$ because of the increased reaction site, which led to an increase in its grafting efficiency, as will be discussed in the section on grafting efficiency and cross-linking density. It should also be noted that higher PDI values were obtained for the grafted samples. Such a case is not uncommon since free-radical polymerization often performs poorly in controlling $\mathrm{M}_{\mathrm{w}}$ and PDI. This is due to the chain scission that was caused by the disproportion process. Additionally, the molecular-weight parameters, heterogeneity in cross-linking, network formation, and chain length lead to more random arrangements and increased PDI. It can also be seen that the type of polymerization and the photoinitiator play a role in increasing or decreasing the PDI; this was clear from the comparison between this work and that done by Li et al. [43]. The PDI of PAN in this work, as a control, was found to be 4.9; however, the PAN synthesized by living polymerization was 1.13. Autoscaled Chromatogram GPC of PAN, LENR 25, ENR- 25, ACN-g-ENR at various mole ratios is shown in Supplementary Information Figure S4.

\subsection{Grafting Efficiency and Crosslinking Density}

The grafting yield (\% GY) and grafting efficiency (\% GE) of the grafted products ACN-g-ENR were directly proportional to the addition of an ACN monomer until they achieved the maximum value at $\mathrm{ACN}_{15}-\mathrm{g}-\mathrm{ENR}_{1}$. It was noted that \% GY and \% GE increased dramatically with the increase in ACN amount, and decreased thereafter, with a further increase in ACN, as explained in Supplementary Information Table S5. It should be noted that the sample $\mathrm{ACN}_{15}-g-\mathrm{ENR}_{1}$ achieved the highest \% GY and \% GE of $64.05 \%$ and $56.59 \%$, respectively. This may be related to the extent of grafting that is controlled by the amount of ACN diffusion and the reaction medium reaching the ENR-25 structure, as discussed earlier. However, after the optimum ratio of $\mathrm{ACN}_{15}-\mathrm{g}-\mathrm{ENR}_{1}$, both $\% \mathrm{GY}$ and \% GE decreased. This could be attributed to the tendency of PAN homopolymer formation as ACN content to increase onto the ENR-25 backbone, thereby increasing the reaction medium viscosity. Eventually, this restricts the motion of the ACN monomers reaching the active sites at the ENR-25 backbones, which directly reduces the rates of grafting [30], as shown in Scheme 1, step 13.

The equilibrium swelling revealed the production of a crosslinking reaction during the grafting of ACN onto ENR-25. This was clear when ENR-25 was immersed in toluene; it dissolved absolutely after 5 days. However, the grafted samples did not completely dissolve in toluene in the same period of time. This could be due to the presence of macroradicals that create the crosslinking during grafting. Supplementary Information 
Figure S6 explained that, when the amount of ACN increased, the swelling ratio was decreased as a result of crosslink density increasing when the amount of ACN increased. Table 2 shows the \% solubility of the grafted products (for non-purified samples) using different organic solvents.

Table 2. Solubility (\%) of the grafted products ACN-g-ENR in different organic solvents.

\begin{tabular}{|c|c|c|c|c|}
\hline$W_{t}$ Solute $\left(W_{1}\right)$ & Solvent (in $5 \mathrm{~mL}$ ) & $\begin{array}{l}\text { Boiling Point } \\
\text { of Solvent }\end{array}$ & $\begin{array}{l}W_{\mathrm{t}} \text { of Solute after } \\
\text { Dissolving }\left(W_{2}\right)\end{array}$ & $\begin{array}{c}\text { Solubility }(\%)=\left(W_{1}-W_{2}\right) \\
\qquad / W_{1} * 100\end{array}$ \\
\hline $0.04 \mathrm{~g}$ & n-Hexane & $68^{\circ} \mathrm{C}$ & $0.0308 \mathrm{~g}$ & $23 \%$ \\
\hline $0.04 \mathrm{~g}$ & Xylene & $138.4^{\circ} \mathrm{C}$ & $0.0089 \mathrm{~g}$ & $78 \%$ * \\
\hline $0.04 \mathrm{~g}$ & Toluene & $110.6^{\circ} \mathrm{C}$ & $0.0307 \mathrm{~g}$ & $23 \%$ \\
\hline $0.04 \mathrm{~g}$ & Tetrahydrofuran & $66^{\circ} \mathrm{C}$ & $0.0171 \mathrm{~g}$ & $57 \%$ \\
\hline $0.04 \mathrm{~g}$ & Chloroform & $61.2^{\circ} \mathrm{C}$ & $0.0230 \mathrm{~g}$ & $43 \%$ \\
\hline $0.04 \mathrm{~g}$ & 2-butanone & $79.64^{\circ} \mathrm{C}$ & $0.0124 \mathrm{~g}$ & $69 \%$ \\
\hline $0.04 \mathrm{~g}$ & Acetone & $56^{\circ} \mathrm{C}$ & $0.0292 \mathrm{~g}$ & $27 \%$ \\
\hline $0.04 \mathrm{~g}$ & DMF & $153^{\circ} \mathrm{C}$ & $0.0237 \mathrm{~g}$ & $41 \%$ \\
\hline $0.04 \mathrm{~g}$ & Dimethyl sulfoxide & $189^{\circ} \mathrm{C}$ & $0.0121 \mathrm{~g}$ & $70 \% * *$ \\
\hline $0.04 \mathrm{~g}$ & Acetonitrile & $82{ }^{\circ} \mathrm{C}$ & $0.0302 \mathrm{~g}$ & $25 \%$ \\
\hline
\end{tabular}

${ }^{*} \&{ }^{* *}$ Xylene and DMSO, respectively, gave the highest percentage $(\%)$ of solubility at $50-60{ }^{\circ} \mathrm{C}$, but at $70-100{ }^{\circ} \mathrm{C}$, both solvents have dissolved the samples completely, especially with purified samples.

\subsection{Thermal Analyses}

DMA analysis was performed to elucidate the changes in storage modulus $(E)$. In general, the change in storage modulus, $E$, is a direct illustration of the intermolecular interaction between the polymers. The storage modulus curve of all grafted samples is categorized into three regions. First, a large value of storage modulus $(19,779$ to $132,353 \mathrm{MPa})$ was noticed at a very low temperature, which is a glassy state. Second, a drastic decrease in $E$ is due to the glass transition region. Third, the $E$ showed a plateau curve, namely, a rubbery state [5]. At a low temperature, the $E$ did not appear to be affected, as the deformation was primarily elastic due to the decrease in molecular motion [44]. The $\mathrm{E}$ value slightly declined between -60 and $-40{ }^{\circ} \mathrm{C}$, then decreased rapidly after $-40{ }^{\circ} \mathrm{C}$ until a rubbery plateau was reached. The samples exhibited closed $E$ at $25^{\circ} \mathrm{C}$ in the range of 55-56,222 MPa. The $\tan \delta$ peak achieved its maximum peak by the reduction in $E$ in the transition region. The behavior is associated with the transition of the glassy-rubbery phase, which is ascribed to the motion of the micro-Brownian of the main chain, also called $\alpha$-relaxation [45]. The value of $T_{\mathrm{g}}$, is given by the highest peak ( $\alpha$-relaxation) of $\tan \delta$ vs. temperature curve, was found at -12 and $-16.63^{\circ} \mathrm{C}$, with $\tan \delta 0.37$ and 1.05 for the $\mathrm{ACN}_{10}-g-\mathrm{ENR}_{1}$ and $\mathrm{ACN}_{15}-g-\mathrm{ENR}_{1}$, respectively.

However, $\mathrm{ACN}_{20}-g$-ENR 1 showed $\alpha$-relaxation, $T_{\mathrm{g}}$ at $13^{\circ} \mathrm{C}$, with another $\beta$-relaxation at $-16.16^{\circ} \mathrm{C}$ with $\tan \delta 0.34$. It was noted that the transition area of $E$ and the position of $\tan \delta$ peak shifted towards the higher temperature, with the increasing mole ratio of ACN to ENR-25, as explained in Figure 6.

By comparing NR, ENR- 25, ENR- 50, Acrylonitrile Butadiene Rubber (NBR) and Acrylonitrile Butadiene Styrene (ABS) were reported by Salaeh [5] and Ramesan and Alex [46]; ACN-g-ENR films showed a large value of $E$ in the rubbery area com-pared to neat NR, ENR- 25, ENR- 50, NBR and ABS, as shown in Table 3. Ramesan and Alex, [44] used Aparene N553 NS, with 34\% bound acrylonitrile content, which is substantially higher compared to this work; however, its mechanical properties were considerably poor. In our case, $A C N-g$-ENR has better mechanical properties. This is evidenced by their higher degree of crystallinity and the strong interaction between ACN and ENR- 25, which generated transient cross-linking. Thus, it displays increased $T_{\mathrm{g}}$ values, as demonstrated in the DSC section. Nevertheless, the tan $\delta$ values of ACN-g-ENR films decreased with increasing $\mathrm{ACN}$ content. This is ascribed to the increase in interfacial bonding [44] as a result of the increase in the crystallinity of grafted products. The DMA result showed that the ratio of $\mathrm{ACN}_{15}-g-\mathrm{ENR}_{1}$ is more flexible, due to it having the highest value of tan 
$\delta$. The ratio of $\mathrm{ACN}_{20}-\mathrm{g}$-ENR 1 showed the highest crosslinking, as explained earlier in crosslinking studies. Thus, it is deduced that the grafting of ACN onto the ENR- 25 matrix was suitable to alter ENR, and then can be used to prepare membranes or composites with high dielectric-thermo-mechanical properties.

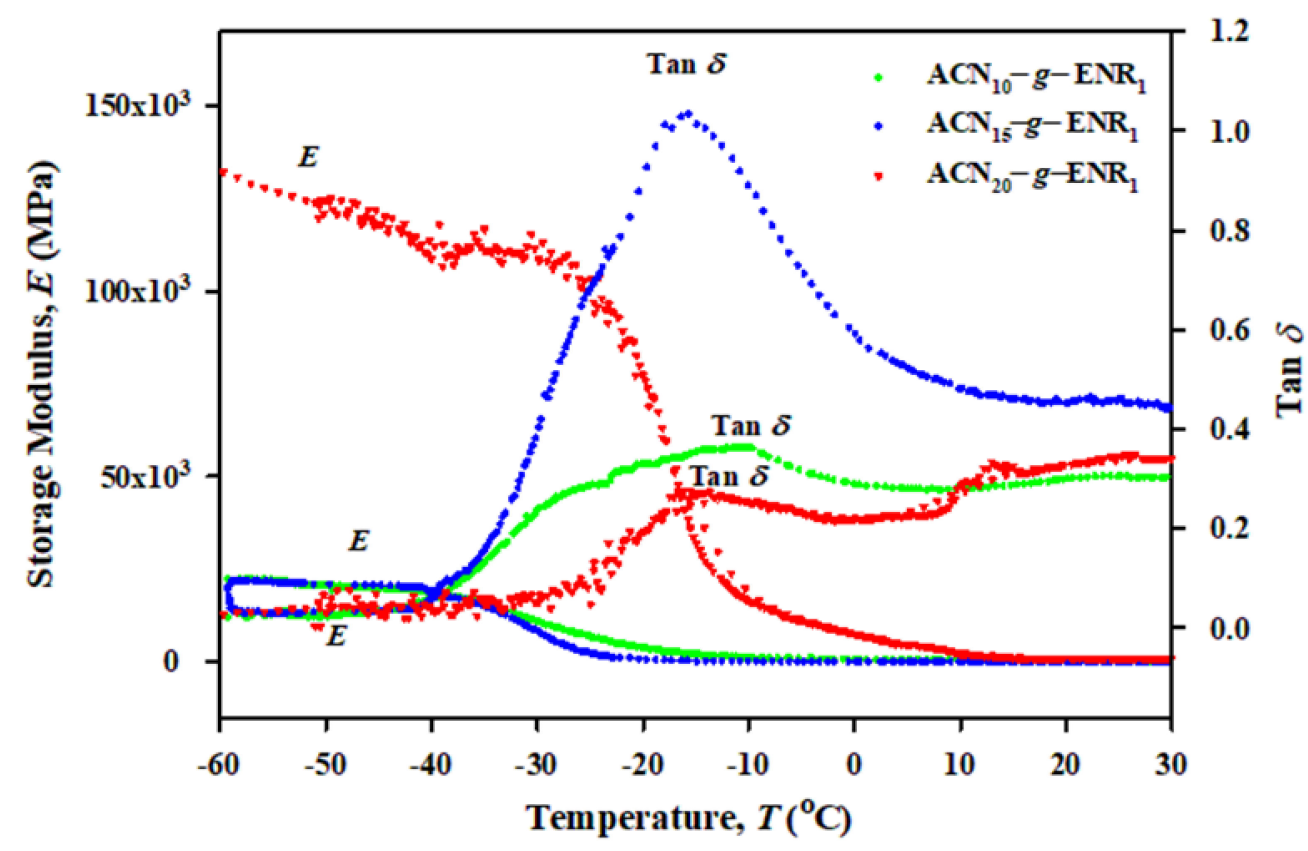

Figure 6. Storage modulus and $\tan \delta$ as a function of temperature for ACN-g-ENR products at different mole ratios.

Table 3. Storage modulus and $\tan \delta$ of ENR- 25 and ACN- $g$-ENR products at different mole ratios.

\begin{tabular}{|c|c|c|c|c|}
\hline \multirow{2}{*}{ Sample ID } & \multicolumn{2}{|c|}{ Storage Modulus, E (MPa) } & \multicolumn{2}{|c|}{$\operatorname{Tan} \delta, T_{\mathrm{g}}$} \\
\hline & At $-60{ }^{\circ} \mathrm{C}$ & At $25^{\circ} \mathrm{C}$ & $\operatorname{Tan} \delta_{\max }$ & $T_{\mathrm{g}}{ }^{\circ} \mathrm{C}$ \\
\hline NR [5] * & 67000 & 1.6 & 2.48 & -49 \\
\hline ENR- $25[5]$ * & 62000 & 2.1 & 2.62 & -24 \\
\hline ENR- $50[5]$ * & 3800 & 1.9 & 2.70 & -5.7 \\
\hline NBR $[46]^{* *}$ & $\sim 100$ & $\sim 1$ & $\sim 1.3$ & -12 \\
\hline $\mathrm{ACN}_{10}-g-\mathrm{ENR}_{1}$ & 22,286 & 713 & 0.37 & -12 \\
\hline $\mathrm{ACN}_{15}-g-\mathrm{ENR}_{1}$ & 19,779 & 55 & 1.05 & -15.73 \\
\hline $\mathrm{ACN}_{20}-g-\mathrm{ENR}_{1}$ & 132,353 & 56,222 & 0.34 & 13 \\
\hline
\end{tabular}

*Salaeh (2014) and ** Ramesan and Alex (2001).

DSC thermograms (second run curves) of the PAN homopolymer, with ENR- 25 as control samples, and ACN-g-ENR at different mole ratios, are illustrated in Figure 7. The $T_{\mathrm{g}}$ for PAN and ENR- 25 was 97 and $-44^{\circ} \mathrm{C}$, respectively. This value is very close to the previously reported $T_{\mathrm{g}}$ of PAN $\left(100{ }^{\circ} \mathrm{C}\right)$, [47], and ENR- $25\left(-40{ }^{\circ} \mathrm{C}\right)$ [7]. However, a sharp exothermic peak between about 240 and $350{ }^{\circ} \mathrm{C}$ in PAN homopolymer is not exhibited in the thermogram, as reported by Preta et al. [48] and Fleming et al. [49], due to the measurement being carried out between -100 and $250{ }^{\circ} \mathrm{C}$. This peak was due to dehydrogenation, oxidation, crosslinking, and cyclization reactions that were initiated by the free-radical mechanism. However, thermogravimetric analysis shows signs of this peak, which will be explained in the TGA analysis section. The thermal stability of ACN-g-ENR samples exhibited a notable enhancement due to the grafting reaction. As summarized in Table 4 , the $T_{\mathrm{g}}$ values increase gradually from -44 to $-34.39^{\circ} \mathrm{C}$. The presence of another $T_{\mathrm{g}}$ was observed at $\sim 103, \sim 103$, and $111^{\circ} \mathrm{C}$ for $\mathrm{ACN}_{10^{-}} g-\mathrm{ENR}_{1}, \mathrm{ACN}_{15^{-}}-\mathrm{ENR}_{1}$, and $\mathrm{ACN}_{20^{-}}$ $g$-ENR 1 , respectively. This is due to the presence of a homopolymer of PAN that was 
cross-linked beside the grafted product, as shown in Scheme 1, step 13. In addition, some peaks were observed at 175 and $205^{\circ} \mathrm{C}$ for the ratio $\mathrm{ACN}_{10}-\mathrm{g}$-ENR $\mathrm{EN}_{1}$, a peak at $180^{\circ} \mathrm{C}$ for the ratio $\mathrm{ACN}_{15}-g$-ENR 1 , and two peaks at 177 and $209^{\circ} \mathrm{C}$ for the ratio $\mathrm{ACN}_{20}-g-\mathrm{ENR}_{1}$. These new peaks also suggest the presence of cross-linking via UV curing. As shown in Figure 7, the grafting of ACN onto ENR-25 causes an increase in $T_{\mathrm{g}}$. As mentioned earlier in the GPC part, this is due to chain scission, which causes the polymer chain to become smaller and leads to transient cross-linking. Table 4 summarizes the main data for the DSC thermal analysis thermograms.

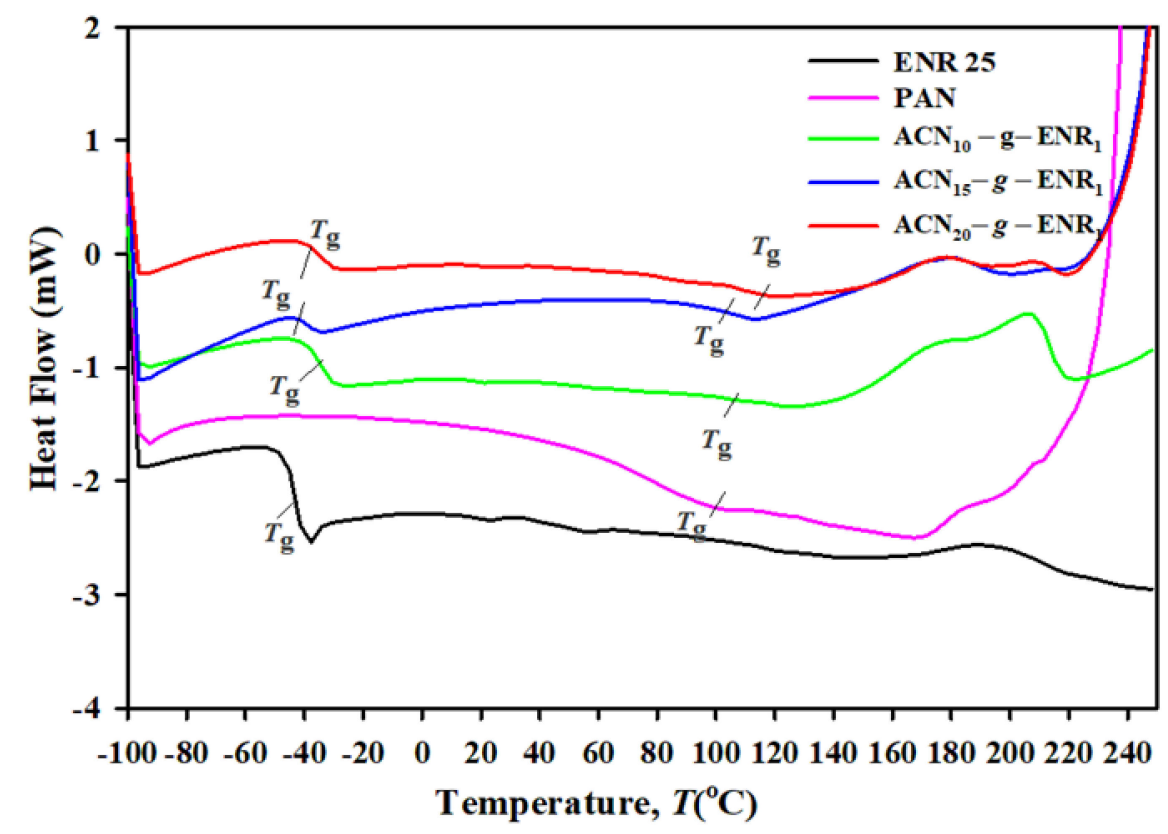

Figure 7. DSC thermograms of PAN, ENR- 25, and ACN-g-ENR products at different mole ratios.

Table 4. Glass transition, $T_{\mathrm{g}}$ and thermal degradation and maximum temperatures values from TGA and DTG curves of PAN, ENR- 25, and ACN-g-ENR products at different mole ratios.

\begin{tabular}{|c|c|c|c|c|c|c|c|c|c|}
\hline \multirow{2}{*}{ Sample ID } & \multicolumn{2}{|c|}{$T_{\mathrm{g}}$} & \multicolumn{2}{|c|}{$\left(50-100{ }^{\circ} \mathrm{C}\right)$} & \multicolumn{2}{|c|}{$\left(100-300{ }^{\circ} \mathrm{C}\right)$} & \multicolumn{3}{|c|}{$T_{\mathrm{d}}\left(300-598^{\circ} \mathrm{C}\right)$} \\
\hline & $T_{\mathrm{g} 1}$ & $T_{\mathrm{g} 2}$ & wt. $\%$ & $T_{\max }$ & wt. $\%$ & $T_{\max }$ & $T_{\mathrm{d}}$ & wt. $\%$ & $T_{\max }$ \\
\hline PAN & 97 & $\mathrm{Nd}$ & 9.71 & $\mathrm{Nd}$ & 11.34 & 237 & 326 & 20.26 & 431 \\
\hline ENR- 25 & -44 & $\mathrm{Nd}$ & 11.70 & 64.24 & 21.82 & $\mathrm{Nd}$ & 338 & 40.22 & 397 \\
\hline $\mathrm{ACN}_{10}-g-\mathrm{ENR}_{1}$ & -34.96 & 102.92 & 12.68 & 65.39 & 22.23 & 202 & 346 & 41.23 & 400 \\
\hline $\mathrm{ACN}_{15}-g-\mathrm{ENR}_{1}$ & -39.25 & 102.59 & 9.81 & 66.65 & 16.63 & 194 & 407 & 32.79 & 414 \\
\hline $\mathrm{ACN}_{20}-g-\mathrm{ENR}_{1}$ & -34.39 & 110.73 & 12.09 & 67.79 & 14.1 & 98 & 365 & 37.28 & 406 \\
\hline
\end{tabular}

Thermogravimetric analysis (TGA) and derivation of thermogravimetric (DTG) were executed to investigate the thermal decomposition of ENR-25, PAN, and grafting products. Figure 8 illustrates the thermal degradation characteristics of ENR-25, PAN, and ACN$g$-ENR films as a function of \% weight loss with temperature. However, about 9-13\% weight loss was noticed for all samples at the temperature range of $50-100{ }^{\circ} \mathrm{C}$. This is due to the evaporation of some remaining solvent trapped inside the samples. All samples exhibited only one thermal degradation stage in the temperature range of $50-600^{\circ} \mathrm{C}$. In the temperature range of $100-300^{\circ} \mathrm{C}$, peaks were detected for all grafted products. These peaks are associated with the dehydrogenation, oxidation, and crosslinking of PAN, as explained in the DSC section. Thermal degradation values higher than neat ENR- 25 were also observed for the grafted samples. This indicates the grafting of ACN onto the ENRbackbone, which is a popular behaviour because of the presence of ACN, which exhibits high thermal stability, as most studies have observed. The values of $T_{\max }$ are higher for 
the grafted samples compared to ENR-25, proving that the grafting of ACN onto ENR25 influences the onset and outset of the grafted thermal degradation [50]. Furthermore, the temperatures of the maximum weight loss rate of ENR- 25 and ACN- $g$-ENR graft samples are different, indicating that grafting ACN onto the ENR-25 backbone changes the maximum weight loss degradation behaviour of the ENR-25 matrix [4]. The main weight loss is due to the chain scission of the grafted ACN and the total decomposition of the rubber matrices. Although there is a reduction in the $M_{\mathrm{wt}}$ of ACN-g-ENR samples, as explained in the GPC section, the grafted samples remained thermally stable, as shown by the TGA results. From these degradations, it can be deduced that the graft products exhibited high thermal stability. This shift can be explained by assuming that the produced grafting and cross-linking of ACN onto ENR-25 improved the thermal stability [8,9,32,51], as shown in Figure 8, which can be used to prepare a membrane with high thermal stability.

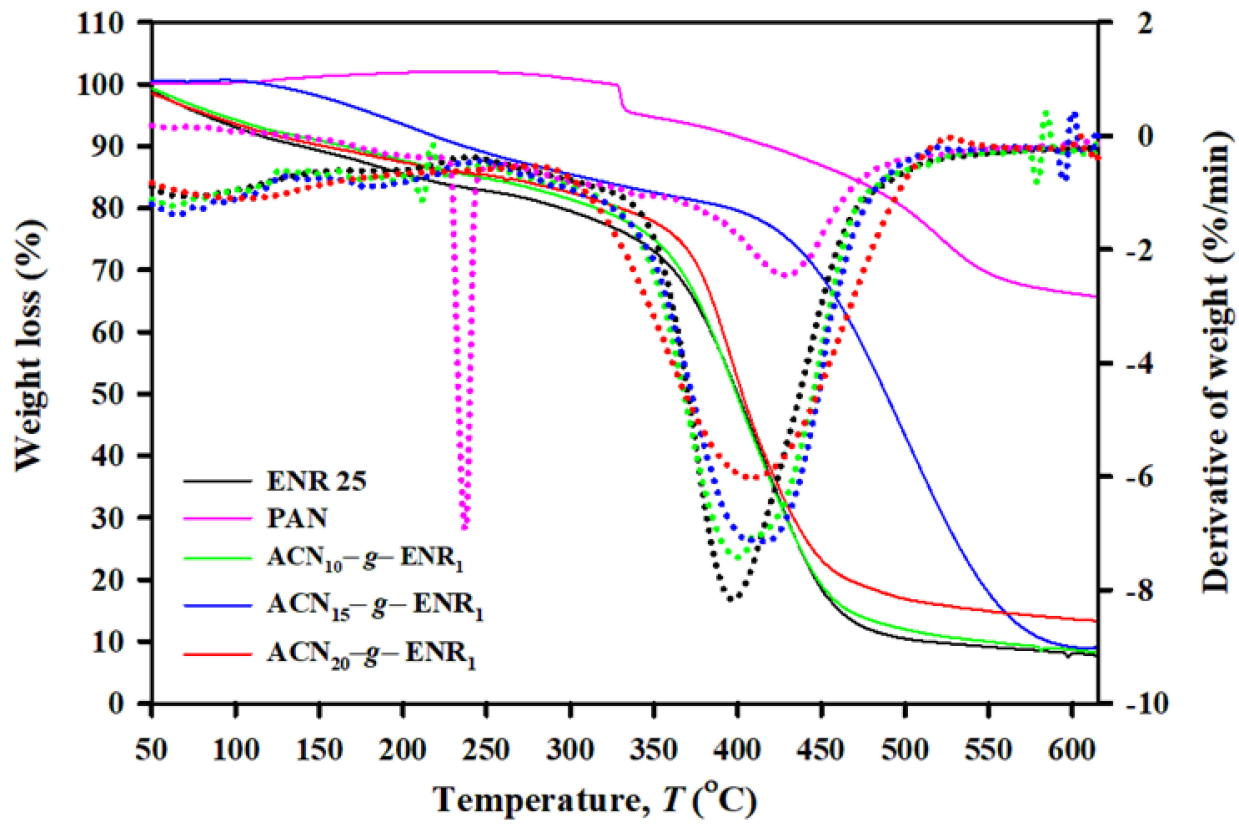

Figure 8. TGA and DTG curves of ENR- 25, PAN, and ACN- $g$-ENR products at various mole ratios (TGA curves (represented by line) and DTG curves (represented by dotted line)).

The TGA result also showed that the $\mathrm{ACN}_{15}-g-\mathrm{ENR}_{1}$ is more stable compared to $\mathrm{ACN}_{10}-\mathrm{g}-\mathrm{ENR}_{1}$ and $\mathrm{ACN}_{20}-\mathrm{g}$-ENR 1 . This is due to this ratio having the highest $\% \mathrm{GY}$ and $\% \mathrm{GE}$, as explained earlier in the grafting studies. It should be pointed out that the residue fraction was high at a temperature of over $500{ }^{\circ} \mathrm{C}$ : around $~ 23.86 \%$, $40.77 \%$, and $36.53 \%$ for $\mathrm{ACN}_{10}-g-\mathrm{ENR}_{1}, \mathrm{ACN}_{15}-g-\mathrm{ENR}_{1}$, and $\mathrm{ACN}_{20}-g-\mathrm{ENR}_{1}$, respectively. This could be due to the scission of the main chains. Nevertheless, the increase in ACN-g-ENR residue with ACN loading is due to undecomposed can, as a temperature of $600^{\circ} \mathrm{C}$ is not sufficient to completely decompose the ACN. According to Salles et al., the complete decomposition of PAN with complete removal of carbon occurs at $1000{ }^{\circ} \mathrm{C}$ [52]. Table 4 lists $T_{\mathrm{d}}, T_{\max }$, and wt. $\%$ for ENR- 25, PAN, and ACN-g-ENR products.

\subsection{Dielectric Spectroscopy Study}

In this work, the dielectric spectroscopy study (DSS) was demonstrated at room temperature and applied to address the influence of grafting on the structural relaxation of the ENR elastomer, as shown in Figure 9. In addition, this aimed to increase understanding the properties of the grafted product and provide a well-characterized polymeric matrix compared to the previous literature. The real permittivity, $\varepsilon_{\mathrm{r}}$, and imaginary permittivity, $\varepsilon_{\mathrm{i}}$, as functions of the frequency for the grafting $\mathrm{ACN}$ on the structure ENR at different mole ratios, were plotted in Figure $9 \mathrm{~b}$,c. It was observed that both $\varepsilon_{r}$ and $\varepsilon_{i}$ decreased with 
frequency due to the orientation of the dipole and the polarization of the displacement, which were unable to follow the changes in the alternating electrical field at high frequency. At high frequencies, the dipoles do not have time to align before the field changes direction, thus resulting in a decrease in charge accumulation. On the contrary, at low frequencies, the dipoles have sufficient time to align with the field before it changes direction. This can be clearly seen as both $\varepsilon_{r}$ and $\varepsilon_{i}$ slowly start to decrease from their initial values, followed by a rapid decrement with increasing frequency, before reaching a nearly constant value. The rapid decrease in $\varepsilon_{r}$ and $\varepsilon_{i}$ values with increasing frequency can be associated with the inability of dipoles in the system to rotate rapidly, leading to a lag between the frequency of oscillating dipole and that of the applied field [53].
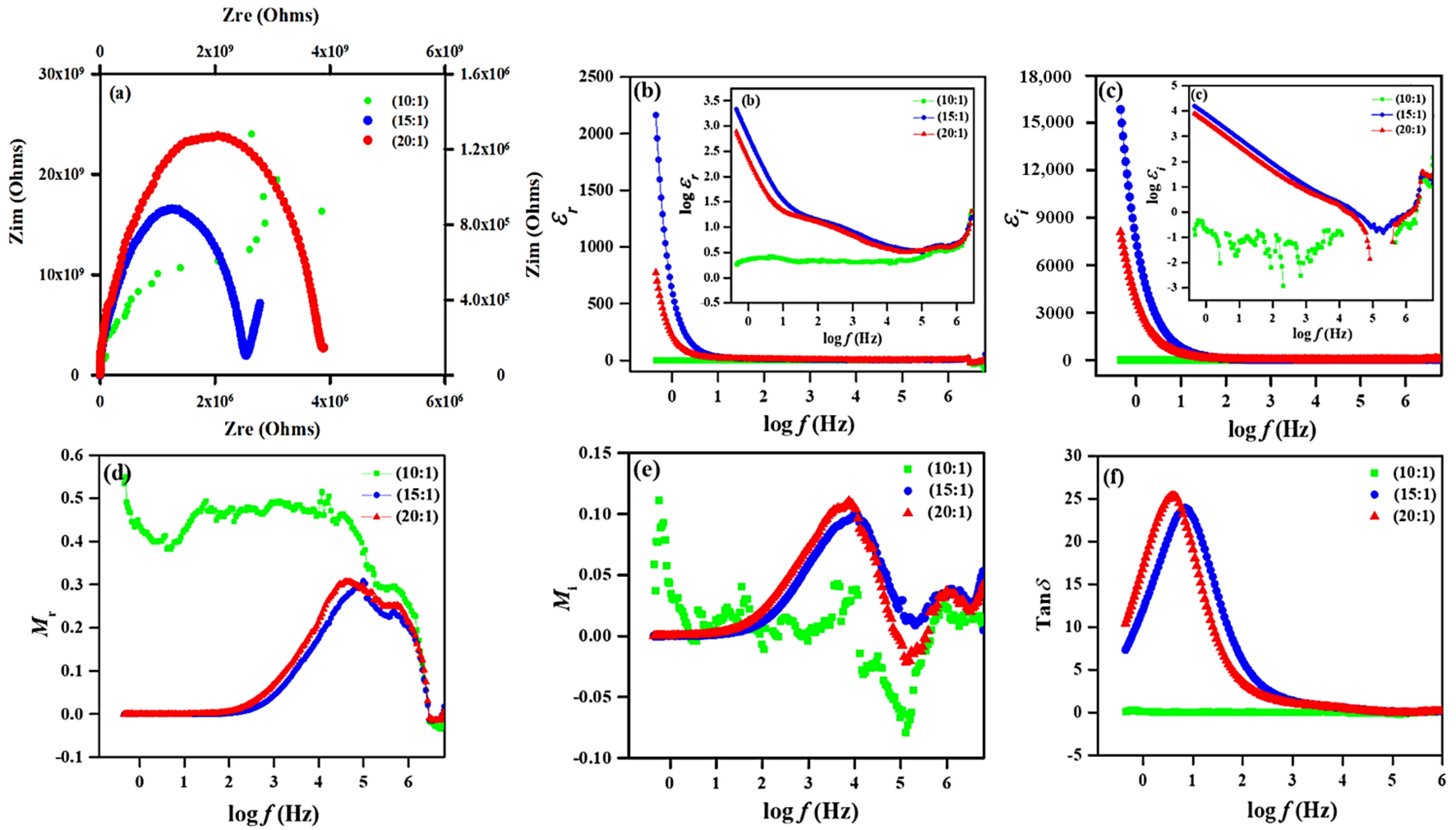

Figure 9. Variation in (a) impedances, (b) $\varepsilon_{\mathrm{r}},(\mathbf{c}) \varepsilon_{\mathrm{i}},(\mathbf{d}) M_{\mathrm{r}},(\mathbf{e}) M_{\mathrm{i}}$, and (f) $\tan \delta$ as a function of frequency $(0.1 \mathrm{~Hz}-1 \mathrm{MHz})$ of $\mathrm{ACN}-\mathrm{g}$-ENR products with different mole ratios and room temperature.

A comparison of our work $\left(\varepsilon_{r}\right.$ and $\left.\varepsilon_{i}\right)$ and previous work by Salaeh [5] is summarized in Table S7. Overall, the values of $\varepsilon_{r}$ and $\varepsilon_{i}$ for ACN-g-ENR were higher compared to pure ENR $25\left(\varepsilon_{r}=3.76\right.$ and $\left.\varepsilon_{i}=0.03\right)$. The $\varepsilon_{r}$ and $\varepsilon_{i}$ values for both $\mathrm{ACN}_{15}-g-\mathrm{ENR}_{1}$ and $\mathrm{ACN}_{20}-\mathrm{g}-\mathrm{ENR}_{1}$ are $\sim 8.04$ and 10.40 and $\sim 6.71$ and 6.87 , respectively. This is attributed to $\mathrm{ACN}$ properties, which also evidenced that $\mathrm{ACN}$ is successfully embedded into the ENR- 25 backbones. Additionally, the high value of $\varepsilon_{r}$ and $\varepsilon_{i}$ in the sample indicates a higher amount of charge carriers and energy losses, respectively [36,54], leading to high charge mobility when the polarity of the electric field changes quickly $[36,54,55]$. Overall, $\mathrm{ACN}_{15}-g$-ENR 1 represents the highest dielectric values and an improvement over ENR samples, possibly indicating that it possessed the highest grafting efficiency, as discussed earlier, and has the lowest $T_{\mathrm{g}}$, as reported in the DSC section.

Besides the permittivity study, the electric modulus can be used to describe the relaxation phenomenon in the material [56]. In Figure 9d,e, two relaxation peaks were observed. The two peaks are attributed to the $\alpha$ and $\beta$-relaxation process, which generally contributes a segmental motion [57] and crosslinking of the formed homopolymer PAN. Here, the observed relaxation behaviour is the result of the combination of two polarization mechanisms, which depend on the physical movement of the charges responsible for 
the dipoles and on the length of time required for their displacement. One mechanism originates from the dielectric properties of the ENR of the polar epoxy group, and the other is the $\mathrm{ACN}$ of the polar nitrile group. In general, the ratio $\mathrm{ACN}_{20}-\mathrm{g}$-ENR 1 gave the highest value of $M_{\mathrm{r}}$ and $M_{\mathrm{i}}$ compared to $\mathrm{ACN}_{15}-g$-ENR 1 . This is ascribed to the higher crosslinking density in the $\mathrm{ACN}_{20}-g$-ENR 1 , as shown in Figure S6. As reported by Zulkifli, [53], both $\alpha$ and $\beta$ relaxation increase with the increase in the amount of cross-linking reaction. However, except for the $\mathrm{ACN}_{10}-g-\mathrm{ENR}_{1}$, there are no real significant changes in electric modulus above the ratio of 10:1 (ACN: ENR).

For the tan delta $(\operatorname{Tan} \delta)$, the relaxation time can be estimated using $\omega \times \tau=2 \pi f_{\mathrm{m}} \times \tau=1$ equation from the maximum $\tan \delta$ vs. frequency curves, as mentioned earlier. The maximum $\tan \delta$ (also known as maximum dielectric loss tangent) is a time constant, which represents the relaxation time associated with the change diffusion process in the sample and is correlated with the plateau of the real part of the conductivity [58]. It can be seen in Figure $9 f$ that $\tan \delta$ increased with increasing values of frequency, to a maximum, and then decreased. At the lower-frequency region, the $\tan \delta$ increased due to the dominance of the Ohmic (active) compared to the capacitive (reactive), while the reverse trend is observed at the high-frequency region [59]. From the results, the value of the obtained $\tau$ is 0.023 and $0.039 \mathrm{~s}$ for $\mathrm{ACN}_{15}-g-\mathrm{ENR}_{1}$ and $\mathrm{ACN}_{20}-g-\mathrm{ENR}_{1}$, respectively. The relaxation time was calculated from the frequency, $f_{\mathrm{m}}$ corresponding to the peak according to the equation reported by Woo et al. [36]. The $\mathrm{ACN}_{15}-g$-ENR 1 sample exhibited the shortest relaxation time, which indicated that ion dynamics are strongly governed by the segmental motion of the polymer chain and increase the rate of segmental dynamics $\left(\tau_{\tan \delta}\right)$, which increases the mobility of ions in the faster-relaxing media [60]. However, no peak is observed for $\mathrm{ACN}_{10}-g-\mathrm{ENR}_{1}$.

It can be concluded that the results of dielectric analysis illustrated that the $\mathrm{ACN}_{15^{-}}$ $g$-ENR 1 sample is suitable to be a host polymer for electrochemical applications, owing to it showing an enhancement in the dielectric behavior compared to the other samples. Supplementary Information Table S7 summarizes the dielectro-thermo-mechanical properties of NR, ENR- 25, ENR-50, and NBR from the previous studies, compared to ACN-g-ENR synthesized at various mole ratios [61-70].

\section{Conclusions}

The grafting of an ACN monomer onto ENR- 25 material, initiated by a DMPA initiator, was successfully conducted by free-radical polymerization at a different mole ratio of ACN to ENR- 25 by grafting from-to. The optimum result for grafting was found for $\mathrm{ACN}_{15}$-g$\mathrm{ENR}_{1}$, with the optimum $\% \mathrm{GY}=64.05 \%$ and $\% \mathrm{GY}=56.59 \%$. However, at a higher ratio of monomer, $M_{\mathrm{W}}$ was increased and PDI decreased. The \% GE and crosslinking density were dramatically increased with an increase in $\mathrm{ACN}$ moles. However, after obtaining the optimum monomer addition for $\mathrm{ACN}_{15}-g$-ENR 1 , both \% GY and \% GE decreased. Thermal analysis showed a high $T_{\mathrm{g}}$ value after the grafting of ACN onto ENR 25, due to lower chain mobility and an improvement in the overall thermal stability. The results of dielectric analysis illustrated that ACN-g-ENR is suitable as a host polymer for electrochemical applications owing to its higher mechanical properties and dielectric permittivity. The results show that the grafting of ACN onto ENR- 25 decreased the molecular weight and increased $T_{\mathrm{g}}$ and the thermal stability. Overall, it may be said that, by comparing NR and ENR-25 to ACN-g-ENR, ACN-g-ENR will introduce the desired properties for ENR-25, which increases its applications in the various applied fields. This may be the first step to achieving an economical production, with a simple and speedy method, for an industrial manufacturing line.

Supplementary Materials: The following are available online at https: / /www.mdpi.com/2073-4 360/13/4/660/s1, Figure S1: 1D 1H-NMR spectra for ACN, PAN, ACN10-g-ENR1, and ACN20-gENR1, Figure S2: 1D 13C-NMR spectra for ACN, PAN, ACN10-g-ENR1, and ACN20-g-ENR1, Figure S3: 2D NMR spectra for ACN, PAN, ACN10-g-ENR1, and ACN20-g-ENR1, Figure S4: Autoscaled Chromatogram GPC of PAN, LENR 25, ENR- 25, ACN10-g-ENR1, ACN15-g-ENR1, and ACN20g-ENR1, Figure S5: Swelling ratio and crosslink density of ACN-g-ENR products at various mole 
ratios using the equilibrium swelling method, Table S1: FTIR's wavenumber assignments of ENR- 25, ACN, PAN, and ACN-g-ENR products at different mole ratios, Table S2: \% GY and \% GE data of PAN, ENR- 25 and ACN-g-ENR products at various mole ratios using Soxhlet method, Table S3: A summary of thermo-mechanical properties as well as the dielectric properties for NR, ENR- 25, ENR50 , and NBR from the previous studies compared to ACN-g-ENR products with various mole ratios.

Author Contributions: R.W. carried out the original draft preparation, data curation, visualization, investigation, and methodology. M.S.S. contributed with review and editing, funding acquisition, conceptualization, validation, administration of the project, and supervision. L.T.K. participated by providing the conceptualization, visualization, validation, reviewing and editing, and supervision; S.I. contributed with supervision and resources. N.S.M. contributed with supervision and resources. A.A. contributed to the administration of the project, and supervision, conceptualization, funding acquisition, and resources. All authors have read and agreed to the published version of the manuscript.

Funding: This research was funded by Universiti Kebangsaan Malaysia (UKM), grant number [UKM-GUP-2019-073].

Institutional Review Board Statement: Not applicable.

Informed Consent Statement: Not applicable.

Data Availability Statement: The data presented in this study are available on request from the corresponding author. The data are not publicly available due to privacy restrictions.

Acknowledgments: The authors acknowledge Universiti Kebangsaan Malaysia (UKM) for supporting this project, government of Yemen, represented by Taiz University for the scholarship, the faculty of science and technology (FST) for the technical support, Centre for Research, and Instrumentation Management (CRIM) Universiti Kebangsaan Malaysia (UKM) for the facilities, and Malaysia Rubber Board (MRB), Sungai Buloh, Selangor, Malaysia for providing the researchers with ENR- 25.

Conflicts of Interest: The authors declare that they have no known competing financial for interests or personal relationships that could have appeared to influence the work reported in this paper.

\section{References}

1. Department of Statistics Malaysia, Monthly Rubber Statistics Malaysia, January 2020. Available online: https://www.dosm.gov. my/v1/index.php?r=column/cthemeByCat\&cat=73\&bul_id=NS85MWFLdDNDb2RWUkpJY09nYW1VQT09\&menu_id=Z0 VTZGU1UHBUT1VJMFlpaXRRR0xpdz09 (accessed on 13 March 2020).

2. Department of Statistics Malaysia, Monthly Rubber Statistics Malaysia, February 2020. Available online: https://www.dosm. gov.my/v1/index.php?r=column/cthemeByCat\&cat=73\&bul_id=RmtHZ1F0dWpwd2VYSWcyajBFakVqdz09\&menu_id=Z0 VTZGU1UHBUT1VJMFlpaXRRR0xpdz09 (accessed on 15 April 2020).

3. Cornish, K. Alternative natural rubber crops: Why should we care? Technol. Innov. 2017, 18, 244-255. [CrossRef]

4. Rooshenass, P.; Yahya, R.; Gan, S.N. Comparison of three different degradation methods to produce liquid epoxidized natural rubber. Rubber Chem. Technol. 2016, 89, 177-198. [CrossRef]

5. Salaeh, S. Processing of Natural Rubber Composites and Blends: Relation between Structure and Properties. Ph.D. Thesis, Université Claude Bernard Lyon 1, Villeurbanne, France, Prince of Songkla University, Pattani, Thailand, 4 July 2014.

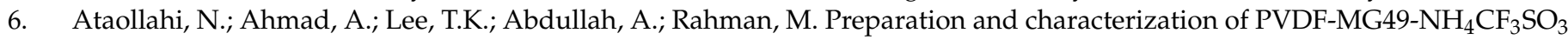
based solid polymer electrolyte. e-Polymers 2014, 14, 115-120. [CrossRef]

7. Harun, F.; Chan, C.H. Electronic Applications of Polymer Electrolytes of Epoxidized Natural Rubber and Its Composites; Springer: Cham, Switzerland, 2016; pp. 37-59.

8. Srirachya, N.; Kobayashi, T.; Boonkerd, K. An alternative crosslinking of epoxidized natural rubber with maleic anhydride. Key Eng. Mater. 2017, 748, 84-90. [CrossRef]

9. Stephens, H.L.; Bhowmick, A.K. (Eds.) Handbook of Elastomers; Marcel Dekker, Inc.: Totnes, UK, 2001.

10. Lee, T.K.; Afiqah, S.; Ahmad, A.; Dahlan, H.M.; Rahman, M.Y.A. Temperature dependence of the conductivity of plasticized poly(vinyl chloride)-low molecular weight liquid 50\% epoxidized natural rubber solid polymer electrolyte. J. Solid State Electrochem. 2012, 16, 2251-2260. [CrossRef]

11. Rahman, M.Y.A.; Ahmad, A.; Lee, T.K.; Farina, Y.; Dahlan, H.M. Effect of ethylene carbonate (EC) plasticizer on poly(vinyl chloride)-liquid 50\% epoxidised natural rubber (LENR50) based polymer electrolyte. Mater. Sci. Appl. 2011, 2, 817-825. [CrossRef]

12. Rahman, M.Y.A.; Ahmad, A.; Lee, T.K.; Farina, Y.; Dahlan, H.M. $\mathrm{LiClO}_{4}$ salt concentration effect on the properties of PVC-modified low molecular weight LENR50-based solid polymer electrolyte. J. Appl. Polym. Sci. 2012, 124, 2227-2233. [CrossRef]

13. Fouassier, J.P.; Allonas, X.; Burget, D. Photopolymerization reactions under visible lights: Principle, mechanisms and examples of applications. Prog. Org. Coatings 2003, 47, 16-36. [CrossRef] 
14. Ates, S.; Aydogan, B.; Torun, L.; Yagci, Y. Synthesis and characterization of triptycene type cross-linker and its use in photoinduced curing applications. Polymer 2010, 51, 825-831. [CrossRef]

15. Dizman, C.; Ates, S.; Torun, L.; Yagci, Y. Synthesis, characterization and photoinduced curing of polysulfones with (meth)acrylate functionalities. Beilstein J. Org. Chem. 2010, 6, 56. [CrossRef]

16. Mishra, M.; Yagci, Y. Handbook of Vinyl Polymers: Radical Polymerization, Process, and Technology; CRC Press: Boca Raton, FL, USA, 2008.

17. Kookarinrat, C.; Paoprasert, P. Versatile one-pot synthesis of grafted-hydrogenated natural rubber. Iran. Polym. J. 2015, 24, 123-133. [CrossRef]

18. Van Zyl, A.J.; Graef, S.M.; Sanderson, R.D.; Klumperman, B.; Pasch, H. Monitoring the grafting of epoxidized natural rubber by size-exclusion chromatography coupled to FTIR spectroscopy. J. Appl. Polym. Sci. 2003, 88, 2539-2549. [CrossRef]

19. Moolsin, S.; Robishaw, N.K. Natural rubber modification by vinyl monomers grafting: A review. Rangsit J. Art Sci. 2011, 5, 99-116.

20. Ratnam, C.T.; Nasir, M.; Baharin, A.; Zaman, K. Effect of blending parameters on electron beam enhancement of PVC/ENR blends. Polym. Plast. Technol. Eng. 2001, 40, 561-575. [CrossRef]

21. Yin, C.; Zhang, Q.; Liu, J.; Gao, Y.; Sun, Y.; Zhang, Q. Preparation and Characterization of Grafted Natural Rubber/Graphene Oxide Nanocomposites. J. Macromol. Sci. Part B 2019, 58, 645-658. [CrossRef]

22. Idris, R.; Bujang, N.H. Epoxidised Natural Rubber Based Polymer Electrolyte Systems for Electrochemical Device Applications. Adv. Mater. Res. 2014, 896, 62-65. [CrossRef]

23. Abd El Salam, H.M.; Sayyh, S.M.; Kamal, E.H.M. Enhancing both the mechanical and chemical properties of paper sheet by graft co-polymerization with acrylonitrile/methyl methacrylate. Beni-Suef Univ. J. Basic Appl. Sci. 2014, 3, $193-202$.

24. Athawale, V.D.; Lele, V. Syntheses and characterisation of graft copolymers of maize starch and methacrylonitrile. Carbohydr. Polym. 2000, 41, 407-416. [CrossRef]

25. Casinos, I. Mechanisms for the radical graft polymerization of vinyl and/or acrylic monomers on cellulose. Polymer 1994, 35, 606-615.

26. Bhattacharya, A.; Rawlins, J.W.; Ray, P. Polymer Grafting and Crosslinking; John Wiley \& Sons: Hoboken, NJ, USA, 2008.

27. Pérez, J.H.; Lopez-Cabarcos, E.; López-Ruiz, B. The application of methacrylate-based polymers to enzyme biosensors. Biomol. Eng. 2006, 23, 233-245. [CrossRef]

28. Adam, C.; Lacoste, J.; Lemaire, J. Photo-oxidation of polyisoprene. Polym. Degrad. Stab. 1991, 32, 51-69. [CrossRef]

29. Odian, G. Principles of Polymerization; John Wiley \& Sons: Hoboken, NJ, USA, 2004.

30. Carbone, N. Photochemical Crosslinking Reactions in Polymers. Ph.D. Thesis, Columbia University, New York, NY, USA, 2012.

31. Awang, N.A.; Salleh, W.N.W.; Hasbullah, H.; Yusof, N.; Aziz, F.; Jaafar, J.; Ismail, A.F. Graft copolymerization of acrylonitrile onto recycled newspapers cellulose pulp. AIP Conf. Proc. 2017, 1885, 020244.

32. Riyajan, S.A.; Sangwan, W.; Leejarkpai, T. Synthesis and properties of a novel epoxidised natural rubber-g-cassava starch polymer and its use as an impact strengthening agent. Plast. Rubber Compos. 2016, 45, 277-285. [CrossRef]

33. Chen, J.S.; Ober, C.K.; Poliks, M.D.; Zhang, Y.; Wiesner, U.; Cohen, C. Controlled degradation of epoxy networks: Analysis of crosslink density and glass transition temperature changes in thermally reworkable thermosets. Polymer 2004, 45, 1939-1950. [CrossRef]

34. Flory, P.J.; Rehner, J., Jr. Statistical mechanics of cross-linked polymer networks I. Rubberlike elasticity. J. Chem. Phys. 1943, 11, 512-520. [CrossRef]

35. Wang, R.; Mei, H.; Ren, W.; Zhang, Y. Grafting modification of epoxidized natural rubber with poly(ethylene glycol) monomethylether carboxylic acid and ionic conductivity of graft polymer composite electrolytes. RSC Adv. 2016, 6, 107021-107028. [CrossRef]

36. Woo, H.J.; Majid, S.R.; Arof, A.K. Dielectric properties and morphology of polymer electrolyte based on poly( $(\varepsilon$-caprolactone) and ammonium thiocyanate. Mater. Chem. Phys. 2012, 134, 755-761. [CrossRef]

37. Basri, N.H.; Mohamed, N.S. Conductivity Studies and Dieletric Behaviour of PVDF-HFP-PVC-LiClO 4 Solid Polymer Electrolyte. Solid State Sci. Technol. 2009, 17, 63-72.

38. Radhi, M.M.; Haider, A.J.; Jameel, Z.N.; Tee, T.W.; Ab Rahman, M.Z.B.; Kassim, A.B. Synthesis and characterization of grafted acrylonitrile on polystyrene modified with activated carbon using gamma-irradiation. Sci. Res. Essays 2012, 7, 790-795.

39. Mas Haris, M.R.H.; Raju, G. Preparation and characterization of biopolymers comprising chitosan-grafted-ENR via acid-induced reaction of ENR50 with chitosan. Express Polym. Lett. 2014, 8, 85-94. [CrossRef]

40. Hamzah, R.; Abu Bakar, M.; Khairuddean, M.; Mohammed, I.A.; Adnan, R. A structural study of epoxidized natural rubber (ENR-50) and its cyclic dithiocarbonate derivative using NMR spectroscopy techniques. Molecules 2012, 17, 10974-10993. [CrossRef] [PubMed]

41. Azizi, H.; Morshedian, J.; Barikani, M.; Wagner, M.H. Correlation between molecular structure parameters and network properties of silane-grafted and moisture cross-linked polyethylenes. Adv. Polym. Technol. 2011, 30, 286-300. [CrossRef]

42. Routray, C.R.; Tosh, B.; Nayak, N. Grafting of polymethyl methacrylate onto cellulose acetate in homogeneous medium using ceric (IV) ion as initiator. Indian J. Chem. Technol. 2013, 20, 202-209.

43. Li, S.; Wang, Y.; Ma, L.; Zhang, X.; Dong, S.; Liu, L.; Zhou, X.; Wang, C.; Shi, Z. Synthesis of PAN with adjustable molecular weight and low polydispersity index (PDI) value via reverse atom transfer radical polymerization. Des. Monomers Polym. 2019, 22, 180-186. [CrossRef]

44. Sasitaran, M.; Manroshan, S.; Lim, C.S.; Veni, B.K.; Ong, S.K.; Gunasunderi, R. Preparation and characterisation of crosslinked natural rubber (SMR CV 60) and epoxidised natural rubber (ENR-50) blends. ASEAN J. Sci. Technol. Dev. 2017, 34, 106-118. [CrossRef] 
45. Zhang, X.; Loo, L.S. Study of glass transition and reinforcement mechanism in polymer/layered silicate nanocomposites. Macromolecules 2009, 42, 5196-5207. [CrossRef]

46. Ramesan, M.T.; Alex, R. Compatibilization of SBR/NBR blends using chemically modified styrene-co-butadiene rubber Part 2. Effect of compatibilizer loading. Polym. Int. 2001, 50, 1298-1308. [CrossRef]

47. Bashir, Z. Polyacrylonitrile, an unusual linear homopolymer with two glass transitions. Indian J. Fibre Text Res. 1999, 24, 1-9.

48. Catta Preta, I.; Sakata, S.; Garcia, G.; Zimmermann, J.; Gale Beck, F.; Giovedi, C. Thermal behavior of polyacrylonitrile polymers synthesized under different conditions and comonomer compositions. J. Therm. Anal. Calorim. 2007, 87, 657-659. [CrossRef]

49. Fleming, R.; Pardini, L.C.; Alves, N.; Garcia, E.; Brito, C., Jr. Synthesis and thermal behavior of polyacrylonitrile/vinylidene chloride copolymer. Polimeros 2014, 24, 259-268. [CrossRef]

50. Montanheiro, T.L.D.A.; Passador, F.R.; De Oliveira, M.P.; Durán, N.; Lemes, A.P. Preparation and Characterization of Maleic Anhydride Grafted Poly (Hydroxybutirate-CO-Hydroxyvalerate)-PHBV-g-MA. Mater. Res. 2016, 19, 229-235. [CrossRef]

51. Qi, R.; Chen, Z.; Zhou, C. Solvothermal preparation of maleic anhydride grafted onto acrylonitrile-butadiene-styrene terpolymer (ABS). Polymer 2005, 46, 4098-4104. [CrossRef]

52. Salles, V.; Bernard, S.; Brioude, A.; Cornu, D.; Miele, P. A new class of boron nitride fibers with tunable properties by combining an electrospinning process and the polymer-derived ceramics route. Nanoscale 2010, 2, 215-217. [CrossRef]

53. Ahmad, Z. Polymer Dielectric Materials. In Dielectric Material; IntechOpen: London, UK, 2012.

54. Sukri, N.; Mohamed, N.S.; Subban, R.H.Y. Dielectric and conduction mechanism studies of PEMA/ENR-50 blend with $\mathrm{LiCF}_{3} \mathrm{SO}_{3}$ salt. AIP Conf. Proc. 2017, 1877, 060002. [CrossRef]

55. Baskaran, R.; Selvasekarapandian, S.; Hirankumar, G.; Bhuvaneswari, M.S. Dielectric and conductivity relaxations in PVAc based polymer electrolytes. Ionics 2004, 10, 129-134. [CrossRef]

56. Hammami, H.; Arous, M.; Lagache, M.; Kallel, A. Study of the interfacial MWS relaxation by dielectric spectroscopy in unidirectional PZT fibres/epoxy resin composites. J. Alloys Compd. 2007, 430, 1-8. [CrossRef]

57. Adohi, B.P.; Brosseau, C. Dielectric relaxation in particle-filled polymer: Influence of the filler particles and thermal treatments. J. Appl. Phys. 2009, 105, 054108. [CrossRef]

58. Valverde, D.; Garcia-Bernabé, A.; Andrio, A.; García-Verdugo, E.; Luis, S.V.; Compañ, V. Free ion diffusivity and charge concentration on cross-linked polymeric ionic liquid iongel films based on sulfonated zwitterionic salts and lithium ions. Phys. Chem. Chem. Phys. 2019, 21, 17923-17932. [CrossRef] [PubMed]

59. Arya, A.; Sharma, A.L. Structural, electrical properties and dielectric relaxations in $\mathrm{Na}+$-ion-conducting solid polymer electrolyte. J. Phys: Condens. Mater. 2018, 30, 165402. [CrossRef] [PubMed]

60. Sengwa, R.J.; Dhatarwal, P.; Choudhary, S. Role of preparation methods on the structural and dielectric properties of plasticized polymer blend electrolytes: Correlation between ionic conductivity and dielectric parameters. Electrochim. Acta 2014, 142, 359-370. [CrossRef]

61. Utara, S.; Boochathum, P. Effect of molecular weight of natural rubber on the compatibility and crystallization behavior of LLDPE/NR blends. Polym. Plast. Technol. Eng. 2011, 50, 1019-1026. [CrossRef]

62. Samantarai, S.; Mahata, D.; Nag, A.; Nando, G.B.; Das, N.C. Functionalization of acrylonitrile butadiene rubber with metapentadecenyl phenol, a multifunctional additive and a renewable resource. Rubb Chem. Technol. 2017, 90, 683-698. [CrossRef]

63. Dürr, C.J.; Hlalele, L.; Schneider-Baumann, M.; Kaiser, A.; Brandau, S.; Barner-Kowollik, C. Determining the MarkHouwink parameters of nitrile rubber: A chromatographic investigation of the NBR microstructure. Polym. Chem. 2013, 4, 4755-4767. [CrossRef]

64. Silva, M.J.D.; Sanches, A.O.; Malmonge, L.F.; Malmonge, J.A. Electrical, mechanical, and thermal analysis of natural rubber/polyaniline-Dbsa composite. Mater. Res. 2014, 17, 59-63. [CrossRef]

65. Rosniza, H.; Bakar, M.A.; Hamid, S.A.; Ismail, J. Cyclopentyl trisilanol silsesquioxanes-modified natural rubber (CpSSQ $(\mathrm{OH})_{3}-$ ENR-50) nanocomposite in the presence of tin (II) chloride dihydrate. Indones. J. Chem. 2007, 7, 111-116. [CrossRef]

66. Aguilar-Bolados, H.; Yazdani-Pedram, M.; Brasero, J.; Lopez-Manchado, M.A. Influence of the surfactant nature on the occurrence of self-assembly between rubber particles and thermally reduced graphite oxide during the preparation of natural rubber nanocomposites. J. Nanomater. 2015, 2015. [CrossRef]

67. Hussin, N.S.; Harun, F.; Chan, C.H. Thermal Properties and Conductivity of Thermally Treated Epoxidized Natural Rubber-Based Solid Polymer Electrolytes. Macromol. Symp. 2017, 376, 1700049. [CrossRef]

68. Zainal, N.; Mohamed, N.S.; Idris, R. Properties of ENR-50 based electrolyte system. Sains Malays. 2013, 42, 481-485.

69. Yang, D.; Ruan, M.; Huang, S.; Wu, Y.; Li, S.; Wang, H.; Shang, Y.; Li, B.; Guo, W.; Zhang, L. Improved electromechanical properties of NBR dielectric composites by poly(dopamine) and silane surface functionalized $\mathrm{TiO}_{2}$ nanoparticles. J. Mater. Chem. C 2016, 4, 7724-7734. [CrossRef]

70. Yang, D.; Kong, X.; Ni, Y.; Gao, D.; Yang, B.; Zhu, Y.; Zhang, L. Novel nitrile-butadiene rubber composites with enhanced thermal conductivity and high dielectric constant. Compos. Part A Appl. Sci. Manuf. 2019, 124, 10544. [CrossRef] 